\title{
TALE and NF-Y co-occupancy marks enhancers of developmental control genes during zygotic genome activation in zebrafish
}

William Stanney III ${ }^{1}$, Franck Ladam¹, Ian J. Donaldson ${ }^{3}$, Teagan J. Parsons ${ }^{2}$ René Maehr $^{2}$, Nicoletta Bobola ${ }^{3}$ and Charles G Sagerström ${ }^{1,4,5,{ }^{*}}$

${ }^{1}$ Department of Biochemistry and Molecular Pharmacology, University of Massachusetts Medical School, Worcester, MA 01605, USA

${ }^{2}$ Program in Molecular Medicine and Diabetes Center of Excellence, University of Massachusetts Medical School, Worcester, MA 01605, USA

${ }^{3}$ Faculty of Biology, Medicine and Health, University of Manchester, Manchester M13 9PT, UK

${ }^{4}$ Lead Contact

${ }^{5}$ Present address: Department of Pediatrics, University of Colorado Medical School, Aurora, CO 80045, USA

*Correspondence: charles.sagerstrom@ucdenver.edu 


\section{SUMMARY}

Animal embryogenesis is initiated by maternal factors, but zygotic genome activation (ZGA) shifts control to the embryo at early blastula stages. ZGA is thought to be mediated by specialized maternally deposited transcription factors (TFs), but here we demonstrate that NF-Y and TALE - TFs with known later roles in embryogenesis - cooccupy unique genomic elements at zebrafish ZGA. We show that these elements are selectively associated with early-expressed genes involved in transcriptional regulation and possess enhancer activity in vivo. In contrast, we find that elements individually occupied by either NF-Y or TALE are associated with genes acting later in development - such that NF-Y controls a cilia gene expression program while TALE TFs control expression of hox genes. We conclude that NF-Y and TALE have a shared role at ZGA, but separate roles later during development, demonstrating that combinations of known TFs can regulate subsets of key developmental genes at vertebrate ZGA.

Keywords: transcription, embryogenesis, maternal, zygotic, enhancer, nucleosome, pioneer factor, epigenetics 


\section{INTRODUCTION}

For animal embryogenesis, initial development of the zygote is controlled by parental material deposited into sperm and oocytes during gametogenesis. The bulk of this material is provided by the oocyte and the duration of the maternally controlled period varies between different animal species. However, embryonic development in all animals eventually switches to zygotic control. This maternal-to-zygotic transition (MZT) is a complex process that involves changes in the cell cycle, chromatin state and gene expression (reviewed in (Vastenhouw et al., 2019)). Zygotic genome activation (ZGA) is a key component of the MZT that establishes gene expression programs driving subsequent embryonic development during gastrulation and organogenesis stages. ZGA is thought to be initiated by the action of maternally provided transcription factors (TFs). Accordingly, the Zelda TF induces expression of many genes at ZGA in Drosophila (Harrison et al., 2011; Liang et al., 2008; Nien et al., 2011), but there is no known Zelda ortholog in vertebrates. Instead, other TFs have been proposed to regulate ZGA in vertebrates. For instance, Nanog, SoxB1 and Oct4/Pou5f1 (a.k.a. Pou5f3 in zebrafish) are maternally deposited in zebrafish and are required for gene expression at zebrafish ZGA (Lee et al., 2013; Leichsenring et al., 2013). Similarly, Dppa2 and Dppa4 are maternally transmitted and act via Dux TFs to activate large numbers of genes at ZGA in mouse and human embryos (De laco et al., 2019; De laco et al., 2017; Eckersley-Maslin et al., 2019; Hendrickson et al., 2017). However, subsequent genetic analyses indicate that Dux is not required for zygotic development in vivo (Chen and Zhang, 2019) and that the requirement for zebrafish Nanog is likely indirect via an effect on extraembryonic tissues (Gagnon et al., 2018), suggesting that vertebrate ZGA is more complicated and that additional TFs are likely involved in this process.

De novo activation of the zygotic gene expression program requires that the maternally transmitted TFs are able to access their binding sites in compacted genomic DNA, a property associated with pioneer factors (reviewed in (Iwafuchi-Doi and Zaret, 2016)). Accordingly, Zelda opens inaccessible genomic regions to permit binding by other TFs (Schulz et al., 2015; Sun et al., 2015) and both Oct4/Pou5f1 and Sox proteins also possess pioneer activity (Soufi et al., 2012; Soufi et al., 2015). Notably, pioneer factors are active at many stages of embryogenesis to establish tissue-specific gene 
expression programs. For instance, FoxA TFs control the initiation of hepatic gene expression (Cirillo et al., 2002; Gualdi et al., 1996) and PU.1 controls myeloid and lymphoid development (Heinz et al., 2010). Since the initiation of tissue specific gene expression programs is conceptually similar to zygotic gene activation, it is possible that pioneer factors with known later roles (e.g. in gastrulation or organogenesis) also act at the ZGA. Accordingly, we recently reported that two TFs of the TALE family (Prep1 and $\mathrm{Pbx} 4)$ - that were originally defined as cooperating with Hox proteins in the activation of tissue-specific gene expression during organogenesis - actually occupy their genomic binding sites already during maternal stages of zebrafish embryogenesis (Ladam et al., 2018). Many of these sites are also occupied by nucleosomes, consistent with previous reports that Pbx TFs possess pioneer activity (Magnani et al., 2011). While we find maternally deposited TALE TFs bound at genomic elements near genes activated at ZGA, they are also bound near genes active later in development (Ladam et al., 2018), suggesting that TALE TFs may have a dual role. Notably, we further demonstrated that a subset of TALE-occupied sites is associated with nearby binding motifs for the NF-Y TF. NF-Y was originally discovered as a ubiquitous basal transcription factor (reviewed in (Dolfini et al., 2012)), but has recently been shown to be maternally deposited in zebrafish, to form protein complexes with TALE TFs and to possess pioneer activity (Ladam et al., 2018; Nardini et al., 2013; Oldfield et al., 2014). Recent work identified NF-Y binding sites near genes activated at ZGA in mouse embryos (Gao et al., 2018; Lu et al., 2016), but NF-Y also binds near many genes acting at later stages of development (Oldfield et al., 2014). Additionally, NF-Y disruption leads to embryonic lethality in mouse (Bhattacharya et al., 2003), but has only mild effects on gene expression at ZGA (Lu et al., 2016).

Here we examine the function of TALE and NF-Y TFs during zebrafish embryogenesis. Our results suggest that these TFs have a shared role at ZGA, but separate roles later during development. In particular, genomic elements individually bound by either NF-Y or TALE TFs are associated with genes acting later in development - such that NF-Y controls a cilia gene expression program while TALE TFs control expression of homeobox genes. In contrast, TALE and NF-Y co-occupy a subset of genomic elements at ZGA that is selectively associated with early-expressed 
genes involved in transcriptional regulation. Accordingly, disruption of NF-Y or TALE function produces phenotypes that share some features - particularly anterior deformations - but that also show unique defects, such as hindbrain abnormalities in TALE-deficient embryos. Notably, the co-occupied genomic elements possess enhancer activity when tested in a transgenesis assay in vivo. We conclude that TALE and NF-Y co-operate to control a subset of transcriptional regulators at ZGA, but also play distinct individual roles later in zygotic development. 


\section{RESULTS}

\section{NF-Y and TALE TFs are required for formation of anterior embryonic structures}

In order to assess the roles of NF-Y and TALE TFs during embryogenesis, we first set out to disrupt their function. Previous work demonstrated that TALE TFs are required for formation of anterior embryonic structures, such that loss of various combinations of TALE factors results in animals with smaller heads, small (or absent) eyes, cardiac edema and hindbrain defects (Choe et al., 2002; Deflorian et al., 2004; Popperl et al., 1995; Popperl et al., 2000; Waskiewicz et al., 2001; Waskiewicz et al., 2002). This similarity in phenotypes is likely due to the fact that multiple TALE factors act together in larger protein complexes, which are rendered ineffective when one or more TALE factors are disrupted (reviewed in (Ladam and Sagerstrom, 2014; Merabet and Mann, 2016)). In preliminary experiments we recently observed abnormal anterior development also upon disruption of NF-Y function (Ladam et al., 2018). Here we extend this analysis to directly compare disruption of TALE factors (using the dominant negative PBCAB construct reported previously; (Choe et al., 2002)) to disruption of NF$Y$ function (using the previously reported NF-YA dominant negative construct; (Mantovani et al., 1994)) and find smaller heads in both cases (Figure 1A-D). A more detailed examination revealed abnormal head cartilage formation ( $53 \%$ of animals with disrupted NF-Y and $79 \%$ of animals with disrupted TALE function; Figure 1E-M) as well as loss of eyes ( $28 \%$ of animals with disrupted NF-Y and $19 \%$ of animals with disrupted TALE function; Figure 1X). Using in situ hybridization to detect expression of pax2 (at the midbrain-hindbrain boundary), krox 20 (in rhombomeres 3 and 5 of the hindbrain) and hoxd4 (in the spinal cord) in $24 \mathrm{hpf}$ embryos, we observed loss of $\mathrm{r} 3 \mathrm{krox} 20$ expression upon TALE disruption (52\% of embryos; as reported previously; (Choe et al., 2002; Deflorian et al., 2004; Popperl et al., 2000; Waskiewicz et al., 2001; Waskiewicz et al., 2002)), but did not detect any effects of NF-Y disruption (Figure N-U, Y). We conclude that both NF-Y and TALE function in formation of the anterior embryo and that TALE TFs have a distinct role in patterning of the hindbrain.

\section{NF-Y and TALE TFs have both shared and independent transcriptional targets}


To identify shared and separate functions of the NF-Y and TALE TFs, we next carried out RNA-seq at $12 \mathrm{hpf}$ of zebrafish development (Figure $2 \mathrm{~A}-\mathrm{C}$; Figure S1A-C). This timepoint was selected in order to ensure broad capture of gene expression changes resulting from disruption of NF-Y and TALE function. We find that disruption of TALE function affects the expression of 1,500 genes (646 downregulated, 854 up-regulated; $F C \geq 1.5, p_{a d j} \leq 0.01$; Figure 2B, D) at 12hpf. Since TALE factors are thought to act primarily as activators of transcription, we focused on genes downregulated upon disruption of TALE function. Applying the DAVID functional annotation tool, we find that TALE-dependent genes are enriched for functions related to transcription (particularly hox genes) as well as for factors controlling embryogenesis (Figure 2F; GO-terms for genes up-regulated upon disruption of TALE function are shown in Figure S1E). Accordingly, an examination of individual TALE-dependent genes identified members of several classes of TFs and developmental control genes (Figure 2G), consistent with the phenotype observed in figure 1. We next examined the effect of disrupting NF-Y function and find that 902 genes are affected (325 downregulated, 577 upregulated; Figure 2C, D) at $12 \mathrm{hpf}$. An analysis of the GO terms associated with NF-Y-dependent genes revealed high enrichment in functions related to cilia and, to a lesser extent, in genes broadly controlling transcription and development (Figure 2H; GO-terms for upregulated genes are shown in Figure S1F). In particular, different classes of TFs, as well as both structural and motor proteins found in cilia are downregulated upon disruption of NF-Y function (Figure 2l).

Since disruption of either NF-Y or the TALE factors produces embryos with shared phenotypes, we next identified genes whose expression is dependent on both NF-Y and TALE function. We find that there are 201 such genes (74 downregulated, 127 upregulated; Figure 2E). Strikingly, the annotation of genes downregulated both upon disruption of TALE function and upon disruption of NF-Y function identifies transcriptional and developmental roles, but not roles associated with cilia (though several terms associated with tubulin function are retained; Figure 2J, K; GO-terms for up-regulated genes are shown in Figure S1G). We refer to this set of genes as 'NFY/TALE co-regulated genes' and note that it is a relatively small population, such that $\sim 23 \%(74 / 325)$ of the NF-Y dependent genes are also dependent on TALE function 
(Figure 2E). These results indicate that NF-Y and TALE TFs co-regulate a set of transcriptional and developmental control genes that is distinct from genes regulated by either NF-Y or TALE alone. Accordingly, a GO term analysis of genes regulated exclusively by NF-Y revealed strong enrichment for cilia genes (Figure S1I), while genes exclusively dependent on TALE function return GO terms enriched for transcriptional regulation such as hox genes (Figure $\mathrm{S} 1 \mathrm{H}$ ).

\section{NF-Y/TALE co-occupied genomic elements are distinct from those occupied by each TF separately}

Given that NF-Y and TALE TFs appear to have both shared and independent functions, we next examined binding of these TFs across the zebrafish genome. In order to determine if these TFs have a role at ZGA, we focused our analysis at 3.5hpf - when zygotic genes are becoming active in zebrafish embryos. We previously used ChIP-seq to characterize Prep1 occupancy and found that this TF is bound at many genomic elements at maternally controlled stages (3.5hpf and earlier; (Choe et al., 2014; Ladam et al., 2018)), consistent with reports that TALE factors are maternally transmitted in zebrafish (Choe et al., 2002; Deflorian et al., 2004; Waskiewicz et al., 2002). Specifically, our analysis identified a 10bp motif (TGATTGACAG; termed the 'DECA motif'; (Chang et al., 1997; Knoepfler and Kamps, 1997)) as the predominant element occupied by Prep1 in 3.5hpf zebrafish embryos. The DECA motif contains two half-sites - one for Pbx proteins (TGAT) and one for Prep factors (TGACAG) - and Pbx factors are known to form dimers with Prep proteins (reviewed in (Ladam and Sagerstrom, 2014)). Accordingly, using ChIP-qPCR we previously demonstrated that zebrafish Pbx4 occupied 11 of 12 tested DECA sites in 3.5hpf zebrafish embryos (Ladam et al., 2018). We have now extended this analysis to the entire zebrafish genome by performing ChIP-seq for Pbx4 at 3.5hpf (Figure 3A-C; Figure S2A). We find that the majority of Pbx4 peaks overlap with a Prep1 peak (94\% overlap at FE $\geq 10$; Figure 3A, B, F; Figure $\mathrm{S} 2 \mathrm{~B}, \mathrm{C}$ ) and that the predominant sequence motif at $\mathrm{Pbx} 4$ binding sites is indistinguishable from the DECA motif observed at Pbx4/Prep1 co-occupied sites (Figure 3D, G). We also find that the distribution of Pbx4 peaks relative to TSSs is similar to that for Prep1 (Figure 30 ), with $\sim 50 \%$ of all binding sites located within $30 \mathrm{~kb}$ 
of an annotated promoter element (Nepal et al., 2013) in both cases, and that sites cooccupied by Pbx4/Prep1 show a similar distribution (Figure 30). GO-term analyses (Figure 3E) revealed that genes associated with $\mathrm{Pbx} 4$ binding sites are enriched for the same transcriptional regulation and embryogenesis functions that we previously identified for genes associated with 3.5hpf Prep1 bound sites (Ladam et al., 2018). As expected, genes associated with Prep1/Pbx4 co-occupied sites return essentially the same GO terms (Figure 3H). Notably, a large number of Prep1 binding sites do not overlap with Pbx4 peaks (Figure 3F). While this could indicate that Prep1 has functions independent of $\mathrm{Pbx} 4$, it may also be a reflection of different affinities of the two antisera. Nevertheless, our observations indicate that $\mathrm{Pbx} 4$ binding takes place primarily at DECA sites in the context of Pbx4/Prep1 heterodimers at this stage of embryogenesis. Here we focused on the Prep1/Pbx4 co-occupied sites and refer to them as 'TALE sites'.

We previously reported that approximately $30 \%$ of TALE-occupied DECA sites observed at 3.5hpf have a CCAAT sequence motif nearby - usually at a distance of 20bp (Ladam et al., 2018). In other systems, such CCAAT boxes serve as binding sites for the heterotrimeric NF-Y transcription factor. Since NF-Y is maternally deposited in zebrafish (Chen et al., 2009), we previously used ChIP-qPCR to test 15 CCAAT boxes located near DECA sites and found that nine were occupied by NF-Y (Ladam et al., 2018). However, the commercial antiserum we used for the ChIP-qPCR experiment is too low affinity for ChIP-seq. Therefore, in order to examine NF-Y binding genomewide, we raised antiserum to zebrafish NF-YA (the sequence-specific DNA binding component of the NF-Y heterotrimer; see Methods section) and carried out ChIP-seq for NF-Y on 3.5hpf zebrafish embryos (Figure 3A, B, I; Figure S2A). As expected, NF-Yoccupied genomic sites are highly enriched for the CCAAT box sequence motif (Figure $3 \mathrm{~J})$, but we find that the distribution of NF-Y peaks in the genome is somewhat different than the distribution of TALE peaks, such that NF-Y appears to be preferentially bound closer to promoters (Figure 30). Further, we find that NF-Y-bound genomic elements are also associated with genes enriched for functions related to transcriptional regulation and embryogenesis (Figure $3 \mathrm{~K}$ ). 
To further address the potential cooperation between NF-Y and TALE TFs, we next examined if NF-Y and TALE peaks co-localize in the zebrafish genome by determining if $200 \mathrm{bp}$ sequences centered on each peak overlapped by at least $1 \mathrm{bp}$ (see Methods section). Using this criterium, we find that approximately $22 \%$ of the NF-Y occupied sites overlap with a TALE-occupied site (corresponding to $17 \%$ of the TALE bound sites; Figure 3A, B, L; Figure S2B, C). Strikingly, motif analyses identified a 27bp sequence motif encompassing both a DECA motif and a CCAAT box (Figure 3M) associated with the NF-Y/TALE co-occupied sites, while sites occupied by TALE alone display a DECA motif (Figure 3P) and those occupied by NF-Y alone contain a CCAAT box (Figure 3Q). GO terms for genes associated with co-occupied sites are again enriched for functions related to transcriptional control, but less so for functions controlling embryogenesis (Figure 3N). Lastly, sites co-occupied by NF-Y and TALE factors show high association with promoters (Figure 30). We conclude that, in the 3.5hpf zebrafish embryo, NF-Y and TALE TFs individually occupy genomic regions associated with both developmental and transcriptional regulators, but also co-occupy an extended binding motif that appears more selectively associated with transcriptional control genes.

\section{NF-Y and TALE co-regulate a subset of early-expressed transcriptional regulators}

While our RNA-seq analysis identified genes regulated by NF-Y and TALE, it is not clear how direct this regulation might be. To begin addressing this question, we first examined whether TALE-dependent genes are associated with genomic elements bound by TALE TFs. We find that, of the 646 genes we identified as being TALEdependent, 52\% (335/646) are found near (as defined using default parameters in GREAT; see Methods section) a TALE occupied element (Figure 4A, B) and these genes are enriched for functions related to embryonic development and transcriptional regulation with a specific emphasis on hox genes (Figure 4C). Similarly, of the 325 genes our RNA-seq analysis showed to be downregulated upon disruption of NF-Y function, we find that 61\% (199/325) are near a NF-Y occupied element (Figure 4A, B). The GO terms for these genes are enriched for functions related to transcriptional regulation, as well as for cilia structure/function (Figure 4D). Hence, 50-60\% of NF-Y 
and TALE-dependent genes are associated with a binding site for the corresponding TF and the functional annotations of these genes show specific enrichment for the same terms as we observed in our RNA-seq analysis - cilia structure/function for NF-Y dependent genes and hox TFs for TALE-dependent genes. Since initial cilia formation and hox activity occurs at late gastrula and segmentation stages in zebrafish (Essner et al., 2002; Prince et al., 1998a; Prince et al., 1998b), these results indicate that NF-Y and TALE TFs control separate gene expression programs at these stages of zebrafish development.

In order to begin assessing co-regulation by NF-Y and TALE TFs, we carried out the reciprocal analysis. In doing so, we find that $55 \%$ of the 646 TALE-dependent genes are associated with an NF-Y occupied site (358/646) and 49\% of the $325 \mathrm{NF}-\mathrm{Y}$ dependent genes are associated with a TALE-occupied element (158/325), indicating that TALE and NF-Y TFs co-regulate a subset of their target genes (Figure 4A, B). To examine this co-regulation further, we next focused specifically on the NF-Y/TALE coregulated genes defined in figure $2 \mathrm{E}, \mathrm{J}, \mathrm{K}$. We find that of the 74 genes in this category, $70 \%$ are associated with an NF-Y (52/74) occupied site and 50\% (37/74) with a TALEoccupied site (Figure 4A, B). Indeed, 49\% of co-regulated genes are found near both NF-Y and TALE occupied sites (36/74). Strikingly, the GO terms of co-regulated genes associated with both NF-Y and TALE-occupied elements converge on functions related to transcriptional regulation and embryonic development (Figure 4E). Further, if we specifically focus on genes that are near regulatory elements with overlapping NFY/TALE peaks (as defined in Figure 3L-N), we find that they function in transcription and regulation of development, but the categories related to cilia and homeobox functions are no longer represented (Figure 4F). Importantly, broad expression of transcriptional and developmental control genes is the first event to take place after ZGA. Accordingly, by analyzing RNA-seq data collected at $6 \mathrm{hpf}$ - shortly after ZGA - we find that genes associated with both NF-Y and TALE-occupied elements are expressed at higher levels than genes that lack such an association (Figure 4G). Hence, our results indicate that genes co-regulated by NF-Y and TALE act uniquely in transcriptional control of embryogenesis at ZGA, while NF-Y and TALE each controls a distinct gene expression program at later stages. 


\section{Genomic elements co-occupied by NF-Y and TALE TFs act as enhancers in vivo} Although our data show that many genomic elements co-occupied by TALE and NF-Y are found near promoters, TALE TFs are known to act at enhancers (Ferretti et al., 2005; Ferretti et al., 2000; Grieder et al., 1997; Jacobs et al., 1999; Popperl et al., 1995; Ryoo and Mann, 1999; Tumpel et al., 2007). Further, while NF-Y was originally identified as acting at promoters (reviewed in (Maity and de Crombrugghe, 1998)), more recent work revealed an important role for NF-Y at tissue-specific enhancers (Oldfield et al., 2014). To explore these relationships in greater detail, we examined the chromatin state at NF-Y/TALE co-occupied elements and found that both H3K4me1 and H3K27ac (that mark enhancers and promoters) are highly enriched already at 4.3hpf and persist at 9hpf (Figure 5A-D). We note that elements bound by NF-Y alone and, to a lesser extent, TALE alone have the same characteristics. In agreement with NF-Y/TALE cooccupied elements driving gene expression at this stage of development, we also find a dramatic increase in H3K4me3 modifications (a mark of active promoters) between 4.3hpf and 9hpf (Figure 5E, F).

To directly test if NF-Y/TALE co-occupied elements act as enhancers in vivo, we used a previously published enhancer assay (Li et al., 2010) and inserted individual genomic elements upstream of the E1b minimal promoter and the GFP reporter gene. We selected eight genomic elements that contain adjacent NF-Y/TALE motifs (as in figure $3 \mathrm{~N}$ ) and that are associated with genes expressed in the anterior embryo (Figure 5G, I, K, M, O; Figure S3N-Q) and used these to generate transgenic zebrafish. Of the eight constructs (named after the identity of the nearest gene), five showed expression in the F0 generation and GFP-positive embryos were raised to generate stable lines (Summarized in Figure S3Q). The remaining three constructs did not show F0 expression and were not considered further. In stable lines for each of the five constructs we detected tissue-restricted GFP expression with each construct producing a distinct pattern (Figure 5G-P). We screened at least two independent founders for each stable line and find that GFP expression is indistinguishable between founders carrying the same construct (Figure S3K, L, Q), indicating that each element imparts a unique tissue specificity to the basal E1b-GFP reporter that is independent of its 
integration site. In some instances, the observed expression pattern is comparable to that of the nearest gene (e.g. fgf8a; Figure $5 \mathrm{~N}$ ), suggesting that it represents an enhancer element controlling expression of the nearby gene. In other instances, the enhancer drives expression in a novel pattern (e.g. yap1; Figure 5P), suggesting that it may control a gene further away, or that the enhancer element tested (which is $\sim 500 \mathrm{bp}$ in length) lacks some inputs required for proper expression of the nearby gene. These results indicate that NF-Y/TALE co-occupied elements act as enhancers in vivo.

We next took two approaches to confirm that the observed expression patterns are dependent on NF-Y and TALE function. First, we expressed the dominant negative NF-Y and TALE constructs in embryos from a cross of the tcf3a:E1b-GFP transgenic line (Figure 6A). We find that GFP expression is dramatically reduced in embryos expressing either dominant negative construct (Figure 6B-E), indicating that expression from the tcf3a genomic element requires both TALE and NF-Y function. This observation was further confirmed by qRT-PCR analysis (Figure 6F). Second, we made use of a distinct transgenesis strategy that allows us to test the effect of mutating the TALE and NF-Y binding sites in a given enhancer element. Specifically, our transgenic construct includes the gamma-crystallin promoter driving GFP along with the candidate enhancer element driving RFP. We find that the wildtype tcf3a and tle3a enhancers drive tissue-specific RFP expression (Figure 6G, K), as expected based on our results in figure 5. However, when we test mutated versions of these elements (where the TALE and NF-Y binding sites have been disrupted), we find that transgenic animals (defined by GFP expression in the eye; Figure 6J, N) lack RFP expression (Figure 6I, M). We conclude that NF-Y/TALE co-occupied elements possess enhancer activity and that this activity requires NF-Y and TALE function.

\section{DISCUSSION}

Our results indicate that NF-Y and TALE TFs co-operate to regulate expression of transcriptional control genes active shortly after ZGA. These co-regulated genes are associated with an extended binding motif containing both TALE binding sites (DECA sites) and NF-Y binding sites (CCAAT boxes). While this motif has been observed previously (Penkov et al., 2013), it had not been assigned a function. This extended 
motif is also consistent with our previous finding that TALE and NF-Y proteins interact to form a complex (Ladam et al., 2018). Notably, the NF-Y and TALE TFs co-occupy these elements already at $3.5 \mathrm{hpf}$ - when ZGA is occurring. In fact, since NF-Y and TALE TFs are maternally deposited, they may be bound at these sites even earlier during embryogenesis. Accordingly, we have previously shown that Prep1 binding may be detected as early as $2 \mathrm{hpf}$ (Choe et al., 2014). Hence, co-occupancy by NF-Y and TALE marks a specific set of key early-acting genes during ZGA and likely even earlier during development. Given the apparently important function of NF-Y/TALE co-regulated genes, it is unclear why our disruption of NF-Y or TALE function does not produce a more severe phenotype. For instance, disruption of Nanog, SoxB1 and Oct4/Pou5f3, which are reported to act at ZGA in zebrafish, causes embryogenesis to stall at blastula stages (Lee et al., 2013). However, complete developmental blockade is achieved only when all three of these factors are disrupted, indicating that they act in combination to drive gene expression at ZGA. Additionally, recent work suggests that disruption of Nanog, which produces the most severe phenotype of the three TFs, may not affect ZGA directly, but instead block formation of essential extraembryonic tissues (Gagnon et al., 2018). Hence, it may be the case that vertebrate ZGA requires the action of multiple TFs and that disruption of any one TF is not sufficient to block ZGA. In agreement with such a model, recent work revealed that disruption of Dux, a TF implicated in murine ZGA, by itself does not block embryonic development (Chen and Zhang, 2019). Additionally, we find that NF-Y/TALE controls a relatively small number of genes at ZGA. This is in contrast to the situation in Drosophila, where the Zelda TF initiates broad gene expression at ZGA (Harrison et al., 2011; Nien et al., 2011), and suggests that multiple TFs may control subsets of genes at vertebrate ZGA.

Interestingly, we also find that NF-Y and TALE TFs act separately to regulate genes that have more specific functions at later stages of development. This is particularly clear for NF-Y, which regulates a cilia-related gene expression program, but also for the TALE TFs that appear preferentially associated with hox gene activity. Both of these processes are ongoing at late gastrula and organogenesis stages accordingly, we detected gene expression changes in these programs by RNA-seq at 12hpf. While our ChIP-seq analyses indicate that genes in the cilia and hox programs 
are associated with NF-Y or TALE occupied elements - suggesting that they are directly regulated by NF-Y and TALE, respectively - we note that this ChIP-seq analysis was done at 3.5hpf. Hence, NF-Y and TALE TFs may remain bound at sites associated with genes in the cilia and hox programs, or new sites may be occupied at later stages. While we do not have ChIP-seq data at $12 \mathrm{hpf}$ for NF-Y, we have reported such data for Prep1 and find a large increase in the number of Prep1 binding sites from 3.5hpf to $12 \mathrm{hpf}$. Importantly, these new sites are enriched near genes involved in hox-dependent functions, such as hindbrain development (Ladam et al., 2018). Hence, our data suggest that NF-Y and TALE co-operate at ZGA before taking on separate roles at later stages. We note that other putative ZGA regulators, such as Nanog and Sox TFs, also have later functions in embryogenesis, suggesting that this may be a generalizable concept.

Our results indicate that the genomic regions co-occupied by NF-Y and TALE TFs function as enhancers. As early as 4.3hpf (the earliest stage for which such data are available), these regions are enriched for histone modifications (H3K4me1 and H3K27ac) indicative of enhancer elements. In fact, in every case that one of the tested enhancers is transmitted by the mother, the resulting off-spring is GFP positive from the earliest stages of embryogenesis (Figure S3A-J) - suggesting that GFP is maternally deposited and that these enhancers may be active already in the maternal germline. H3K4me3 modifications (indicative of active transcription) are low at 4.3hpf, but increase by $9 \mathrm{hpf}$, consistent with these enhancer elements being located near genes that are activated shortly after ZGA. Genomic elements occupied by either NF-Y or TALE also possess features indicative of enhancers, but, as discussed above, they are instead associated with later expressed genes. We also demonstrate that both NF-Y and TALE activity is required for the enhancer elements to drive gene expression in vivo, but it is not yet clear what specific functions are contributed by each TF. Previous work has suggested that both NF-Y and TALE may represent pioneer factors (Magnani et al., 2011; Nardini et al., 2013). Accordingly, we recently showed that many 3.5hpf TALE-bound sites are also occupied by nucleosomes (Ladam et al., 2018), suggesting that these TFs may be able to access their binding sites in nucleosomal DNA. Previous work has also demonstrated that TALE TFs can recruit histone modifying enzymes 
(Choe et al., 2014; Choe et al., 2009; Saleh et al., 2000) and may therefore promote the deposition of histone marks. Notably, we previously tested several of the NF-Y/TALE co-occupied elements for enhancer activity in HEK293 cells and failed to detect activity (Ladam et al., 2018). Also, both NF-Y and TALE are ubiquitously expressed during embryogenesis and therefore unlikely to mediate the tissue-specific expression we observe in the transgenic lines. Hence, it is possible that NF-Y and TALE are generally required for enhancer activity (possibly by rearranging nucleosomes and promoting histone modifications), but that additional tissue-specific TFs (that are present in embryos, but not in HEK293 cells) also act at these enhancers to drive expression in specific patterns. 


\section{ACKNOWLEDGEMENTS}

This work was supported by NIH grant NS038183 to CGS, BBSRC grant BB/N00907X/1 to NB and NIH grant DP3DK111898 to RM.

\section{AUTHOR CONTRIBUTIONS}

Conceptualization, C.G.S., W.S., F.L. and N.B; Methodology, W.S. and C.G.S; Formal analysis, W.S., and I.J.D.; Investigation, W.S. and F.L.; Writing - Original Draft. C.G.S.; Writing - Review and Editing; W.S., F.L., I.J.D, T.J.P, R.M., N.B., and C.G.S.;

Visualization, W.S.; Resources; T.J.P. and R.M.; Supervision, C.G.S., R.M., and N.B.; Project Administration, C.G.S.; Funding Acquisition, C.G.S., R.M., and N.B.

\section{DECLARATION OF INTERESTS}

The authors declare no competing interests. 


\section{FIGURE LEGENDS}

\section{Figure 1: Disruption of NF-Y or TALE function affects anterior embryonic}

development. Zebrafish embryos were left uninjected (A, E, F, N, O) or injected with either control mRNA (GFP; $B, G, H, P, Q$ ), mRNA encoding a TALE dominant negative construct (PBCAB; C, I, J, R, S) or mRNA encoding an NF-Y dominant negative construct (NF-YA DN; D, K, L, T-W) at the 1-2 cell stage and raised to $24 \mathrm{hpf}(\mathrm{N}-\mathrm{W})$, $28 \mathrm{hpf}(A-D)$ or $5 \mathrm{dpf}(E-L)$. Embryos were either left untreated (A-D), stained with alcian blue (E-L) or processed for detection of pax2 (at the mid/hindbrain boundary), krox20 (in rhombomeres 3 and 5) and hoxd4 (in the spinal cord) transcripts by in situ hybridization $(\mathrm{N}-\mathrm{W})$. White arrows highlight differences in eye morphology (A-L), black arrows highlight differences in head cartilage formation (E-L) and orange arrows indicate differences in rhombomere 3 krox20 expression ( $\mathrm{N}-\mathrm{U})$. Tables summarize effects of TALE or NF-Y disruption on head cartilage formation (M), eye formation (X) and gene expression $(\mathrm{Y})$. Panels $\mathrm{V}$ and $\mathrm{W}$ show representative images of embryos scored as having gross abnormalities in panel $X$. Embryos are shown in lateral (A-D, F, H, J, L, N, $\mathrm{P}, \mathrm{R}, \mathrm{T}, \mathrm{V})$ or dorsal $(\mathrm{E}, \mathrm{G}, \mathrm{I}, \mathrm{K}, \mathrm{O}, \mathrm{Q}, \mathrm{S}, \mathrm{U}, \mathrm{W})$ views.

Figure 2: NF-Y and TALE TFs have both shared and independent transcriptional targets. (A) Schematic of RNA-seq experiments. (B-C) Scatterplots of gene expression in PBCAB vs GFP-injected (B) and NF-YA DN vs GFP-injected (C) zebrafish embryos (expression presented as log2 of average TPM for multiple replicates; see methods). Expression of genes highlighted in orange is significantly different at $12 \mathrm{hpf}$ (padj $\leq 0.01$; Wald test in DESeq2). (D) Number of genes differentially expressed in PBCAB (left) or NF-YA DN (right) relative to GFP-injected embryos ( $p$-adj $\leq 0.01$; fold-change $\geq 1.5$ ). (E) Breakdown of downregulated (left) and upregulated (right) genes exclusive or common to each experimental condition. ( $F, H, J)$ DAVID analyses showing the 25 most significant GO terms (EASE Score) associated with genes downregulated by PBCAB $(F)$, NF-YA DN $(H)$, and common to both $(J)$. Blue bars correspond to transcriptionrelated, green to embryogenesis-related, orange to homeodomain-related, yellow to cilia-related, and gray to other ontologies. (G, I, K) Selected genes downregulated by 
PBCAB (G), NF-YA DN (I), or both (K). Color coding is the same as in $(F, H, J)$. See also Figure S1.

Figure 3: NF-Y/TALE co-occupied genomic elements are distinct from those occupied by each TF separately

(A-B) Representative UCSC Genome Browser tracks for NF-YA, Pbx4 and Prep1 ChIPseq analyses at 3.5hpf. (C, F, I, L) Venn diagrams showing the overlap (at least $1 \mathrm{bp}$ shared between 200bp fragments centered on peaks) of two Pbx4 ChIP-seq replicates (C), the overlap of Pbx4 and Prep1 ChIP-seq peaks (F), the overlap of two NF-YA ChIPseq replicates $(I)$ and the overlap of TALE and NF-Y ChIP-seq peaks (L). (D, G, J, M) The top sequence motif returned by MEME for Pbx4-occupied sites (D), Pbx4/Prep1 cooccupied sites (G), NF-YA occupied sites (J) and TALE/NF-YA co-occupied sites (M). (E, H, K, N) The top 25 gene ontology (GO) terms returned by the GREAT analysis tool for genes associated with Pbx4-occupied sites (E), Pbx4/Prep1 co-occupied sites $(H)$, NF-YA occupied sites (K) and TALE/NF-YA co-occupied sites (N). (O) Chart showing percent of ChIP-seq peaks found within $5 \mathrm{kB}$ or $30 \mathrm{kB}$ of a promoter. $(P, Q)$ Top sequence motif returned by MEME for peaks bound by TALE, but not NF-YA $(P)$ and peaks bound by NF-YA, but not TALE (Q). Only peaks with a 10-fold or greater enrichment over input ( $F E \geq 10)$ were considered for the analyses in C-I. See also Figure S2.

Figure 4: NF-Y and TALE co-regulate a subset of early-expressed transcriptional regulators. (A) Table showing correlation between NF-Y and/or TALE-dependent genes and binding by the corresponding TF at a nearby site. (ChIP peaks enriched by 4-fold or greater over input were considered). (B) Graphical breakdown of NF-Y and/or TALE occupancy near NF-Y and/or TALE-dependent genes. (C-F) Top GO terms returned by DAVID for TALE-dependent genes associated with TALE peaks (C), NF-Y dependent genes associated with NF-YA peaks (D), TALE/NF-Y dependent genes associated with both NF-YA and TALE peaks (E), and TALE/NF-Y dependent genes associated with overlapping TALE and NF-YA peaks (F). Blue bars correspond to transcription-related, green to embryogenesis-related, orange to homeodomain-related, 
yellow to cilia-related, and gray bars to other ontologies. (G) Box chart showing expression levels as log2(average TPM) for NF-Y/TALE-dependent genes with and without nearby TALE/NF-YA peaks.

Figure 5: Genomic elements co-occupied by NF-Y and TALE TFs act as enhancers in vivo. (A-F) Average histone mark signals at genomic regions containing only TALE peaks (dark blue), only NF-YA peaks (light blue), or NF-YA/TALE peaks (yellow) for H3K27ac at 4.3hpf (A) and 9hpf (B), H3K4me1 at 4.3hpf (C) and 9hpf (D), H3K4me3 at 4.3hpf (E) and 9hpf (F). (G, I, K, M, O) UCSC Genome Browser tracks showing NF-YA, Pbx4, and Prep1 ChIP-seq data for the tcf3a (G), tle3a (I), dachb (K), fgf8a (M) and yap1 (O) loci. The diagrams above the tracks show the putative enhancer region in green, DECA motifs in orange and CCAAT boxes in blue. $(\mathrm{H}, \mathrm{J}, \mathrm{L}, \mathrm{N}, \mathrm{P})$ GFP expression in 24hpf F1 tcf3a:E1b-GFP (H), tle3a:E1b-GFP (J), dachb:E1b-GFP (L), fgf8a:E1b-GFP $(N)$ and yap1:E1b-GFP $(P)$ transgenic embryos resulting from crosses between male founders and wild type females. See also Figure S3.

Figure 6: Disruption of TALE and NF-Y function reduces enhancer activity. (A) Schematic showing workflow for dominant negative disruption of tcf3a:E1b-GFP. (B-D) Representative images showing no GFP (B), weak GFP (C), and strong GFP (D) of dominant negative-injected embryos. (E) Distribution of GFP expression in uninjected embryos and embryos injected with PBCAB, NF-YA DN or control RNA. (F) RT-qPCRbased detection of GFP expression in embryos injected with PBCAB, NF-YA DN or control RNA. Data are shown as mean +/- SEM. Statistical test: unpaired t-test (G-N) Representative examples of RFP (G, K, I, M) and GFP (H, L, J, N) signal in tcf3aWT:sv40 (G, H), tcf3a-mut:sv40 (I, J), tle3a-WT:sv40 (K, L) and tle3a-mut:sv40 (M, N) embryos at 32hpf. Insets in panels $\mathrm{L}, \mathrm{J}, \mathrm{N}$ show higher magnification of GFP expression in lens. Note that embryo in panels $\mathrm{G}, \mathrm{H}$ is at a later stage than embryos in panels I-N. (O) Table quantifying results from experiment in panels G-N. 


\section{STAR METHODS}

\section{Lead Contact and Materials Availability}

Further information and requests for resources and reagents should be directed to and will be fulfilled by the Lead Contact, Charles Sagerström

(charles.sagerstrom@ucdenver.edu).

RNA-seq data has been deposited in GEO under accession number GSE133459.

ChIP-seq data has been deposited in ArrayExpress under accession number XX.

\section{Experimental Model and Subject Details}

\section{Care of zebrafish}

The Institutional Animal Care and Use Committee (IACUC) of the University of Massachusetts Medical School approved all procedures involving zebrafish. Adult EkkWill zebrafish were maintained at $28^{\circ} \mathrm{C}$ in groups at a maximum density of 12 individuals per liter with constant flow. To collect embryos for timing-sensitive experiments, one adult male fish and one adult female fish were placed in separate chambers of a $500 \mathrm{~mL}$ tank overnight then placed together the following morning for no more than 30 minutes. For experiments that were not timing-sensitive, both adults were placed in the same chamber overnight. Eggs were collected in $10 \mathrm{~cm}$ dishes, immersed in egg water $(60 \mu \mathrm{g} / \mathrm{mL}$ Instant Ocean, $0.0002 \%$ methylene blue), and maintained in an incubator at $29^{\circ} \mathrm{C}$. Dead and unfertilized eggs were manually removed after two hours.

\section{Method Details}

\section{Generation of $m R N A$ for injection}

Capped messenger RNAs encoding the dominant negative NF-YA (NF-YA DN;

(Mantovani et al., 1994)), dominant negative Pbx4 (PBCAB; (Choe et al., 2002)) proteins were generated from $2 \mu \mathrm{g}$ of Notl-digested linearized pCS2+ plasmids using the mMessage mMachine SP6 Transcription Kit (ThermoFisher Scientific) according to the manufacturer's guidelines. The RNA was purified using the RNeasy column with DNase treatment (Qiagen) according to the manufacturer's guidelines. RNA quality was assessed on a $1 \%$ agarose gel and its concentration was measured on a NanoDrop instrument. 300pg of RNA injection mix containing water and $0.1 \%$ phenol red was 
injected into zebrafish embryos at the 1-cell stage. Injected embryos were raised to the proper stage according to animal care guidelines.

\section{Characterization of TALE and NF-Y phenotypes}

For gross phenotype assessment, $24 \mathrm{hpf}$ zebrafish embryos were placed on glass slides in $80 \%$ glycerol. For alcian blue staining, all incubations and washes took place on a nutator. $5 \mathrm{dpf}$ zebrafish embryos were fixed overnight in $4 \%$ phosphate-buffered paraformaldehyde. Following fixation, the embryos were washed in $0.1 \%$ phosphatebuffered Tween-20 (PBST) and bleached in 30\% hydrogen peroxide for 2 hours. Once bleached, the embryos were rinsed twice in PBST and then stained overnight in alcian blue solution ( $1 \%$ hydrochloric acid $(\mathrm{HCl}), 70 \%$ ethanol, $0.1 \%$ alcian blue). After staining, the embryos were washed five times in acidic ethanol $(\mathrm{HCl}-\mathrm{EtOH} ; 5 \% \mathrm{HCl}$, $70 \%$ ethanol) with the final wash lasting 20 minutes. The embryos were then rehydrated in a series of 10 -minute incubations of $75 \% \mathrm{HCl}-\mathrm{EtOH} / 25 \%$ water, $50 \% \mathrm{HCl}-\mathrm{EtOH} / 50 \%$ water, $25 \% \mathrm{HCl}-\mathrm{EtOH} / 75 \%$ water, and $100 \%$ water and imaged. For in situ hybridizations, all incubations and washes took place on a nutator. $24 \mathrm{hpf}$ zebrafish embryos were fixed overnight in $4 \%$ phosphate-buffered paraformaldehyde. Following fixation, the embryos were washed in a 1:1 methanol:PBST solution, then PBST, and then treated with $1 \mu \mathrm{g} / \mathrm{mL}$ Proteinase $\mathrm{K}$ in PBST for 2 minutes. The embryos were washed once with $-20^{\circ} \mathrm{C}$ acetone and twice with PBST then incubated at $70^{\circ} \mathrm{C}$ for 1 hour in Hyb+tRNA Buffer (50\% formamide, 5X saline sodium citrate (SSC), 9.2mM citric acid, 0.5\% Tween-20, $50 \mu \mathrm{g} / \mathrm{mL}$ heparin, $500 \mu \mathrm{g} / \mathrm{mL}$ tRNA). Next, the embryos were transferred to pax $2 / \mathrm{krox} 20 /$ hoxd4a probe solution and incubated at $70^{\circ} \mathrm{C}$ overnight. After probe incubation, the embryos were washed sequentially for 10 minutes each at $70^{\circ} \mathrm{C}$ in Hyb Wash Buffer (50\% formamide, 5X saline sodium citrate (SSC), 9.2mM citric acid, 0.5\% Tween-20, $50 \mu \mathrm{g} / \mathrm{mL}$ heparin), 2:1 Hyb:2xSSC, 1:2 Hyb:2xSSC, 2xSSC, $0.2 \times S S C$, and 0.1xSSC, then blocked in Blocking Solution $(2 \%$ lamb serum and $2 \mu \mathrm{g} / \mu \mathrm{L}$ bovine serum albumin in PBST) at $4^{\circ} \mathrm{C}$ for 1 hour. The embryos were then incubated with $0.01 \%$ anti-DIG antibody at $4^{\circ} \mathrm{C}$ overnight. Following antibody treatment, the embryos were washed four times with PBST and two times with Staining Buffer $(0.1 \mathrm{M}$ Tris $\mathrm{pH} 9.5,50 \mathrm{mM} \mathrm{MgCl}_{2}, 125 \mathrm{mM} \mathrm{NaCl}, 0.5 \%$ Tween20) then stained with Staining 
Solution (100 mg/mL polyvinyl alcohol, 0.35\% 5-Bromo-4-chloro-3-indolyl phosphate, $0.45 \%$ 4-Nitro blue tetrazolium) at $37^{\circ} \mathrm{C}$ until the color developed. The embryos were then washed four times in PBST and scored. Sample size for phenotypic analyses was based on previous published reports that these dominant negative constructs produce phenotypes in $>85 \%$ of injected embryos (Choe et al., 2002; Deflorian et al., 2004; Ladam et al., 2018; Waskiewicz et al., 2001). Embryos were randomly selected for inclusion in injected or control pools. No animals were excluded and experiments were not blinded.

\section{RNA extraction}

Zebrafish embryos were injected with either PBCAB, NF-YA DN, GFP, or antisense NFYA DN mRNA as described above. At the desired timepoint, embryos were collected into three biological replicates of 50-100 embryos per condition. Dead animals were counted, but excluded from RNA extraction procedures. No other animals were excluded, and selection was not blinded. Each sample was placed in $1 \mathrm{~mL}$ of Trizol and frozen at $-80^{\circ} \mathrm{C}$ to help break up embryos. Once thawed, the embryos were broken up by pipette and $250 \mu \mathrm{L}$ of chloroform was added to each sample followed by vigorous shaking and a 3-minute incubation at room temperature. The samples were then centrifuged at $12,000^{*} \mathrm{~g}$ for 15 minutes at $4^{\circ} \mathrm{C}$ and the aqueous phase was transferred to a new tube with $500 \mathrm{~mL}$ of isopropanol and $10 \mu \mathrm{g}$ of GlycoBlue (ThermoFisher Scientific). The samples were vortexed, incubated at room temperature for 10 minutes, and then centrifuged at $12,000^{*} \mathrm{~g}$ for 15 minutes at $4^{\circ} \mathrm{C}$. The supernatant was removed, and the pellet washed in $75 \%$ ethanol then centrifuged at $7,500^{*} \mathrm{~g}$ for 5 minutes at room temperature. The supernatant was once again removed, and the pellet was air-dried at room temperature for 10 minutes before resuspension in $50 \mu \mathrm{L}$ of water. The samples were then further purified and treated with DNase using the RNeasy Column kit (Qiagen) and eluted in $30 \mu \mathrm{L}$ of water.

\section{RNA-seq library preparation and deep sequencing}

The concentration and quality of each sample was assessed on a Bioanalyzer (Agilent), with all samples having a minimum RNA Quality Number of 8.0 and $28 S / 18 S$ ratio of 


\section{0. $4 \mu \mathrm{g}$ of each sample of RNA was shipped to BGI for library preparation and} sequencing. Polyadenylated RNAs were selected using oligo dT beads and then fragmented. N6 random primers were then used to reverse transcribe the library into double-stranded cDNA. A minimum of 20 million single-end $50 \mathrm{bp}$ reads were then generated with the BGISEQ-500 platform.

\section{$R T-q P C R$}

The concentration of each sample was assessed on a NanoDrop instrument. $1 \mu \mathrm{g}$ of RNA was reverse transcribed using the High Capacity cDNA Reverse Transcription Kit (ThermoFisher Scientific). To measure the quantity of select mRNAs, $25 \mu \mathrm{L}$ samples were prepared using $2 \mu \mathrm{L}$ of cDNA, $0.2 \mathrm{mM}$ of forward and reverse primer for each pair, and SYBR Green qPCR Master Mix (Bimake) according to the manufacturer's guidelines. Measurements were made on a 7300 Real-Time PCR System (Applied Biosystems).

\section{Generation of NF-YA Antiserum}

Zebrafish NF-YA antiserum was prepared by ABClonal Technology. DNA encoding amino acids 1-328 of zebrafish NF-YA was cloned into the vector pET-28a-SUMO, containing a 12aa SUMO tag and a 6aa His tag. The vector was transformed into the $E$. coli Rosetta strain and the antigen peptide was induced with $0.8 \mathrm{mM}$ IPTG at $37^{\circ} \mathrm{C}$ for 4 hours. Small-scale antigen expression was confirmed by Western blot, showing a band at $\sim 58 \mathrm{kDa}$ corresponding to the peptide. The peptide was purified, appearing in both the supernatant and inclusion bodies. The concentration in the supernatant was $2 \mathrm{mg} / \mathrm{mL}$, which was deemed appropriate for immunization. Two rabbits were used for immunization and serum was collected on Day 52. The antiserum was tested by ELISA and deemed of sufficient quality with an OD450 > 0.4 at a 1:64,000 dilution. The antibody was purified via antigen affinity purification, with the polyclonal antibody concentration from animal \#E7260 at $4.25 \mathrm{mg} / \mathrm{mL}$ and from animal \#E7621 at $4.66 \mathrm{mg} / \mathrm{mL}$. The antibodies were tested via Western blot at a 1:1000 dilution with 10, 5, 1 , and $0.5 \mathrm{ng}$ of antigen. Bands of $\sim 60 \mathrm{kDa}$ were observed for antibodies from both animals at all four antigen concentrations. 


\section{ChIP-seq}

Groups of $\sim 5,000$ embryos (for Pbx4) and $\sim 10,000$ embryos (for NF-YA) were collected at 3.5hpf and dechorionated in 1X pronase. The embryos were then dissociated by pipette, fixed in $2 \%$ formaldehyde in PBS for 10 minutes at room temperature, quenched with $125 \mathrm{mM}$ glycine, and flash-frozen in liquid nitrogen. Processing of cell pellets followed the protocol previously described (Amin et al., 2015). Nuclei were isolated in L1 Buffer (50mM Tris- $\mathrm{HCl}$ pH 8.0, 2mM EDTA, 0.1\% NP-40, 10\% glycerol, $1 \mathrm{mM}$ PMSF) then lysed in SDS Lysis Buffer (50mM Tris-HCI pH 8.0, 10mM EDTA, 1\% SDS). Chromatin was sheared to an average length of 300bp using a Palmer immersion sonicator (Three 1-minute rounds of $10 \mathrm{~s}$ on/2s off at $40 \%$ amplitude) and diluted 1:10 in ChIP Dilution Buffer (50 mM Tris-HCl pH8.0, 5 mM EDTA, 200 mM NaCl, 0.5\% NP-40, $1 \mathrm{mM}$ PMSF). The samples were pre-cleared with $50 \mu \mathrm{L}$ of Protein A Dynabeads (ThermoFisher Scientific) at $4^{\circ} \mathrm{C}$ for 3 hours, then Input samples were set aside and stored at $-80^{\circ} \mathrm{C}$. Next, $10 \mu \mathrm{L}$ of the appropriate antiserum was added (anti-Pbx4 or antiNF-YA) and the samples were incubated rotating at $4^{\circ} \mathrm{C}$ overnight. The immune complexes were precipitated onto $50 \mu \mathrm{L}$ of Protein A Dynabeads, which were washed five times with Wash Buffer (20 mM Tris-HCl pH8.0, 2 mM EDTA, $500 \mathrm{mM} \mathrm{NaCl}, 1 \%$ NP-40, 0.1\% SDS, 1 mM PMSF), three times with LiCl Buffer (20 mM Tris- $\mathrm{HCl}$ pH8.0, 2 mM EDTA, $500 \mathrm{mM} \mathrm{LiCl,} \mathrm{1 \%} \mathrm{NP-40,} \mathrm{0.1 \%} \mathrm{SDS,} 1 \mathrm{mM}$ PMSF), and three times with TE Buffer (10 mM Tris-HCl pH8.0, 1 mM EDTA, 1 mM PMSF). To elute chromatin, the beads were incubated in 50 $\mu \mathrm{L}$ of fresh Elution Buffer with shaking at 1,500 RPM for 15 minutes at $25^{\circ} \mathrm{C}$ then 15 minutes at $65^{\circ} \mathrm{C}$. To reverse crosslinks, $2 \mu \mathrm{L}$ of $5 \mathrm{M}$ sodium chloride was added to the samples, which were then incubated at $65^{\circ} \mathrm{C}$ overnight. Purification of the DNA was accomplished using the MicroChIP Dia Pure Column kit (Diagenode) according to the manufacturer's guidelines with an $11 \mu \mathrm{L}$ elution. To quantify the concentration of DNA, $1 \mu \mathrm{L}$ of each sample was passed through the dsDNA HS Assay (ThermoFisher Scientific) according to the manufacturer's guidelines and quantified on a Qubit device.

\section{ChIP-seq library preparation and deep sequencing}


ChIP-seq libraries were prepared using the MicroPlex Library Preparation Kit v2 (Diagenode) according to the manufacturer's guidelines. The entirety of each ChIP sample was used and Input samples were either diluted to the same concentration as their corresponding ChIP sample or, if the concentration of the corresponding ChIP sample was below the Qubit's range, diluted to $0.2 \mathrm{ng} / \mu \mathrm{L}$. Following library synthesis, an Illumina HiSeq4000 Sequencer was used to sequence the libraries.

\section{E1b-GFP-Tol2 cloning}

Putative enhancers of $\sim 500 \mathrm{bp}$ centered on Prep1 peaks near DECA sites and CCAAT boxes were amplified via PCR from 24hpf wild-type zebrafish genomic DNA using specific primers with Xhol sites (tcf3a, tle3a, dachb, fgf8a, pax5, her6, prdm14) or Bglll sites (yap1) flanking either end (Table S1). The fragments were ligated into the E1bGFP-tol2 (Birnbaum et al., 2012; Li et al., 2010) empty backbone digested with Xhol or Bglll and transformed into competent DH5alpha E. coli cells (New England Biolabs). The amplified vector was validated by Sanger sequencing and purified using the Plasmid Maxi Kit (Qiagen).

\section{Generation of pTransgenesis donor vectors}

Mutant enhancers were generated by changing DECA sites contained within each enhancer to the sequence CGGTTGGTGC, which has been shown to prevent TALE binding (Vlachakis et al., 2000), and CCAAT boxes to the sequence ATGCG. Both mutant and wild-type versions of each enhancer were generated using gBlock technology (Integrated DNA Technologies). Due to limitations in gBlock synthesis, a 34bp AT-rich region at the 3' end of the tcf3a enhancer could not be included compared to the E1b-GFP-tol2 version. A-tails were added to each end of the gBlock fragments using OneTaq Hot Start DNA Polymerase (NEB) (50ng of gBlock DNA, 1 unit of OneTaq Hot Start DNA Polymerase, 1X OneTaq Standard Reaction Buffer, 0.05mM dATP, $1.5 \mathrm{mM} \mathrm{MgCl}_{2}$ ) and incubating the samples at $70^{\circ} \mathrm{C}$ for 30 minutes. $1 \mu \mathrm{L}$ of $\mathrm{A}$ tailed gBlock fragment solution was then cloned into the $\mathrm{PCR} 8$ vector using the pCR8/GW/TOPO TA Cloning Kit (ThermoFisher Scientific) according to the manufacturer's guidelines. The product was transformed into TOP10 chemically 
competent cells, validated by Sanger sequencing, and then purified using the Plasmid Midi Kit (Qiagen).

\section{Generation of pTransgenesis vectors}

pTransgenesis vectors were assembled using the LR Clonase II Plus enzyme mix (ThermoFisher Scientific). Four cassettes were assembled in one reaction, with gammacrystallin:venusGFP as the p1 cassette (European Xenopus Resource Center (EXRC)), gBlock enhancers in pCR8 as the p2 cassette and Tol2/I-Scel-CH4-SAR/I-Scel/Tol2/Pelement (EXRC) as the pDest-4 cassette. The p3.13 cassette was generated by ligating a BamHI/Bglll-digested gBlock (containing the SV40 minimal promoter) into BamHIdigested p3.13 Katushka-RFP plasmid (EXRC). 10fmol of each of the p1, p2, and p3 cassettes were combined with $20 \mathrm{fmol}$ of $\mathrm{p} 4$ cassette and $2 \mu \mathrm{L}$ of LR Clonase II Plus enzyme mix for the $\mathrm{LR}$ reaction in $10 \mu \mathrm{L}$. The reaction was incubated at $25^{\circ} \mathrm{C}$ for 16 hours then treated with Proteinase $\mathrm{K}$ at $37^{\circ} \mathrm{C}$ for 10 minutes. $2 \mu \mathrm{L}$ of $\mathrm{LR}$ reaction product was transformed into Top10 chemically competent cells, validated by Sanger sequencing, and then purified using the Plasmid Maxi Kit (Qiagen).

\section{Generation and observation of transgenic animals}

Injection mixes containing 100ng/ $\mu \mathrm{L}$ of E1b-GFP-Tol2 or pTransgenesis vector, $100 \mathrm{ng} / \mu \mathrm{L}$ of Tol2 mRNA, and $0.1 \%$ phenol red were injected into wild-type zebrafish embryos at the 1-cell stage. The animals were observed for transient fluorescence for the first week, then raised to adulthood. Mature fish were crossed with wild-type fish and the offspring were observed for fluorescence. For E1b-GFP-Tol2 fish, GFP was observed as early as $18 \mathrm{hpf}$. For pTransgenesis fish, RFP expression and GFP expression overlap was best observed at 32hpf, with RFP being apparent sooner and disappearing by $\sim 48 \mathrm{hpf}$ while GFP persisted after that time. Thus, any fish that appeared to be RFP+/GFP- were separated and observed for GFP expression at a later timepoint.

\section{Quantification and Statistical Analysis}

RNA-seq analysis 
RNA-seq analysis was performed using the University of Massachusetts Medical School Dolphin web interface. Ribosomal RNA reads were filtered out and FastQC was used to assess the quality of the remaining reads. RSEM_v1.2.28 with parameters -p4 --bowtiee 70 --bowtie-chunkmbs 100 ( $\mathrm{Li}$ and Dewey, 2011) was used to align the reads to the DanRer10 zebrafish transcriptome and normalize gene expression to transcripts per million (TPM). This revealed that PBCAB replicate 2 underperformed relative to the other samples and was excluded from further analysis. DeSeq2 (Anders and Huber, 2010) was used to identify differentially-expressed genes between three independent biological replicates of $12 \mathrm{hpf}$ embryos injected with GFP and three independent biological replicates of $12 \mathrm{hpf}$ embryos injected with NF-YA DN or between three independent biological replicates of $1 \mathrm{hpf}$ embryos injected with GFP and two independent biological replicates of $12 \mathrm{hpf}$ embryos injected with PBCAB. DEBrowser was used to identify outliers among the replicates. To compensate for the exclusion of one replicate in GFP versus PBCAB analysis, only differentially expressed genes with a p-adj $\leq 0.01$ (Benjamini and Hochberg FDR) were considered for analysis.

\section{ChIP-seq Data Processing}

All eight ChIP-seq fastq files (two independent 3.5hpf Pbx4 biological replicates, two independent 3.5hpf NF-YA biological replicates, and matched input DNA controls for each) contained $76 \mathrm{bp}$ paired-end sequences. The raw sequence quality was assessed with FastQC (https://www.bioinformatics.babraham.ac.uk/projects/fastqc/) and Fastqscreen (https://www.bioinformatics.babraham.ac.uk/projects/fastq_screen/). Next, remaining adapter reads were filtered out and poor-quality 3 ' end sequences were trimmed with Trimmomatic version 0.36 (Bolger et al., 2014) using default parameters for ILLUMINACLIP and SLIDINGWINDOW and MINLENGTH set to 50bp. Using Bowtie2 version 2.2.3 (Langmead and Salzberg, 2012), the processed reads were then mapped to UCSC browser zebrafish genome release GRCz10 (danRer10/September 2014) (Tyner et al., 2017), and the mapped reads were further filtered with SAMtools view version 0.1.19 (Li et al., 2009) (with flags used -f 2 -q30) to remove reads with poor mapping quality and discordant mapped read pairs. To call peaks, the data, excluding reads that mapped to the mitochondrial genome and unassembled contigs in the 
assembly, was next passed through MACS2 version 2.1.0.20140616 (Zhang et al., 2008) with the q-value threshold set to 0.05 and default parameters except that the effective genome size was set to $1.03 \mathrm{e} 9$ (this equates to $75 \%$ of the total genome sequence, excluding 'N' bases).

\section{ChIP-seq Analysis}

Since the biological replicates for each factor demonstrated robust overlap, the sum of the two replicates was used for all subsequent analyses, by including all peaks meeting the selected cutoff in at least one of the biological replicates. Three different cutoffs were considered: all peaks with a fold enrichment $(F E) \geq 10$, all peaks with a $F E \geq 4$, and the top $10 \%$ of all peaks in each data set. The FE $\geq 10$ cutoff showed the highest overlap between $\mathrm{Pbx} 4$ and Prep1 peaks as a percentage of the total $\mathrm{Pbx} 4$ peaks, and was selected as the best cutoff for ChIP-seq analysis (Supplementary Figure 3C). For a larger set of peaks, FE $\geq 4$ peaks were considered for comparison to RNA-seq data (Figure 4).

\section{ChIP peak overlap analysis}

In the text, we use the term 'overlap' to indicate peaks identified as follows: ChIP peaks shared between different data sets were identified with the Intersect tool and exclusive peaks were identified using the Subtract tool in Galaxy (Goecks et al., 2010). All coordinates used were 200bp in length centered on peak summits and considered overlapping if they shared one or more base pairs.

\section{qPCR Analysis}

ddCt values were calculated from raw Ct values according to the formula $0.5^{\mathrm{Ct}}$. Average ddCt values were then calculated by taking the mean of all three biological replicates. The ddCt of each GFP replicate was then normalized to the average gapdh ddCt according to the formula ddCtGFP/average $\mathrm{ddCt}_{\text {gapdh }}$ and then the mean of the normalized values was determined. Error bars were calculated based on the standard deviation of the three normalized GFP replicates in Excel. To determine whether the 
dominant negative conditions were significantly different from the control condition, an unpaired t-test was used in Excel, with p-values $<0.05$ considered significant.

\section{Determination of nearest genes to ChIP peaks}

The number of Ensembl zebrafish transcription start sites within $5 \mathrm{~kb}$ or $30 \mathrm{~kb}$ of the summit of ChIP peaks was determined using the bedtools suite (Quinlan and Hall, 2010) in the Galaxy toolshed (Goecks et al., 2010). ChIP peak coordinates in danrer10 were converted to danrer7 (Zv9) using the LiftOver tool in the UCSC browser. The identities of genes near ChIP peaks were determined by the GREAT software version 3.0.0 (Hiller et al., 2013; McLean et al., 2010) using the he default settings of basal plus extension with proximal set to $5 \mathrm{~kb}$ upstream and $1 \mathrm{~kb}$ downstream and distal set to $1,000 \mathrm{~kb}$.

\section{GO term analysis}

Gene ontology (GO) terms enriched within different sets of genes were determined using DAVID version 6.8 (Huang da et al., 2009a, b). GO terms were ranked according to the EASE score, which was calculated based on a modified Fisher's exact $p$-value, and graphed as the -log10 of that value.

\section{DNA binding motif analysis}

Significantly enriched binding motifs were identified using MEME and DREME within the MEME-Suite version 4.11.1 (Bailey et al., 2009; Machanick and Bailey, 2011). Both MEME and DREME were run according to their default settings. CENTRIMO was also run with default settings to determine the distribution of discovered motifs relative to ChIP peaks.

\section{Chromatin feature analysis}

Version 2.0 of the Deeptools (Ramirez et al., 2014) toolset in the Galaxy toolshed was used to create mean score profiles and heatmaps. Using the computeMatrix tool with region inputs of BED files containing ChIP coodinates and sample inputs of wiggle files from previously published data sets downloaded from GEO (Key Resources Table), 
signal matrices were generated in reference-point mode with the center set as the reference point. The distance upstream of the start sites and downstream of the end sites were set to $1000 \mathrm{bp}$ with a bin size of $25 \mathrm{bp}$ and ranked by mean signal when necessary. Heatmaps and profiles were generated from the matrices using the plotHeatmap and plotProfile tools respectively. The previously-published H3K27ac, $\mathrm{H} 3 \mathrm{~K} 4 \mathrm{me} 1, \mathrm{H} 3 \mathrm{~K} 4 \mathrm{me}$, and MNase data sets were all performed at 4.3hpf, which is somewhat later than the Pbx4, NF-YA, and Prep1 ChIP-seq experiments performed at 3.5hpf; however, asynchronous development in zebrafish embryos and large sample sizes make considerable overlap likely.

\section{Data and Code Availability}

RNA-seq data is available in GEO under accession number GSE133459 and ChIP-seq data is available in ArrayExpress under accession number E-MTAB-8137.

\section{Key Resources Table}

\begin{tabular}{|c|c|c|}
\hline Reagent or Resource & Source/Reference & Identifier \\
\hline \multicolumn{3}{|l|}{ Antibodies } \\
\hline Rabbit polyclonal anti-zebrafish Pbx & (Choe et al., 2009) & $\mathrm{N} / \mathrm{A}$ \\
\hline $\begin{array}{l}\text { Rabbit polyclonal anti-zebrafish NF- } \\
\text { YA }\end{array}$ & This paper & $\mathrm{N} / \mathrm{A}$ \\
\hline \multicolumn{3}{|l|}{ Bacterial and Virus Strains } \\
\hline $\begin{array}{l}\text { Subcloning Efficiency DH5 } \alpha \\
\text { competent cells }\end{array}$ & ThermoFisher Scientific & $18265-017$ \\
\hline $\begin{array}{l}\text { OneShot Top } 10 \text { chemically } \\
\text { competent cells }\end{array}$ & ThermoFisher Scientific & C404003 \\
\hline \multicolumn{3}{|l|}{$\begin{array}{l}\text { Chemicals, Peptides, and } \\
\text { Recombinant Proteins }\end{array}$} \\
\hline Protein-A Dynabeads & ThermoFisher Scientific & 10001D \\
\hline Notl & New England Biolabs & R0189S \\
\hline Xhol & New England Biolabs & R0146S \\
\hline BgIII & New England Biolabs & R0144S \\
\hline \multicolumn{3}{|l|}{ Critical Commercial Assays } \\
\hline $\begin{array}{l}\text { mMESSAGE mMACHINE SP6 } \\
\text { Transcription Kit }\end{array}$ & ThermoFisher Scientific & AM1340 \\
\hline RNeasy Mini Kit & Qiagen & 74104 \\
\hline DIG DNA Labeling Mix & Millipore Sigma & 11277065910 \\
\hline Trizol & ThermoFisher Scientific & 15596026 \\
\hline GlycoBlue & ThermoFisher Scientific & AM9515 \\
\hline MicroPure DiaChIP Columns & Diagenode & C03040001 \\
\hline
\end{tabular}




\begin{tabular}{|c|c|c|}
\hline dsDNA HS Assay & ThermoFisher Scientific & Q32851 \\
\hline $\begin{array}{l}\text { MicroPlex Library Preparation Kit } \\
\text { v2 }\end{array}$ & Diagenode & C05010012 \\
\hline OneTaq Hot Start DNA Polymerase & New England Biolabs & M0481L \\
\hline pCR8/GW/TOPO & ThermoFisher Scientific & $45-0642$ \\
\hline Plasmid Midi/Maxi Kit & Qiagen & $12143 / 12163$ \\
\hline LR Clonase II Plus Enzyme Mix & ThermoFisher Scientific & $12538-120$ \\
\hline $\begin{array}{l}\text { High Capacity cDNA Reverse } \\
\text { Transcription Kit }\end{array}$ & ThermoFisher Scientific & 4368814 \\
\hline SYBR Green qPCR Master Mix & Bimake & B21203 \\
\hline \multicolumn{3}{|l|}{ Deposited Data } \\
\hline $\begin{array}{l}\text { Pbx4 ChIP-seq and Inputs in } 3.5 \mathrm{hpf} \\
\text { zebrafish embryos }\end{array}$ & This paper & E-MTAB-8137 \\
\hline $\begin{array}{l}\text { NF-YA ChIP-seq and Inputs in } 3.5 \\
\text { hpf zebrafish embryos }\end{array}$ & This paper & E-MTAB-8137 \\
\hline $\begin{array}{l}\text { PBCAB and GFP RNA-seq in } 12 \mathrm{hpf} \\
\text { zebrafish embryos }\end{array}$ & This paper & GSE133459 \\
\hline $\begin{array}{l}\text { NF-YA DN and GFP RNA-seq in } 12 \\
\text { hpf zebrafish embryos }\end{array}$ & This paper & GSE133459 \\
\hline $\begin{array}{l}\text { Prep1 ChIP-seq and Inputs in } 3.5 \\
\text { hpf zebrafish embryos }\end{array}$ & (Ladam et al., 2018) & E-MTAB-5967 \\
\hline $\begin{array}{l}\text { H3K27ac ChIP-seq in dome } \\
\text { zebrafish embryos, WIG files }\end{array}$ & $\begin{array}{l}\text { (Bogdanovic et al., } \\
\text { 2012) }\end{array}$ & GSM915197 \\
\hline $\begin{array}{l}\text { H3K4me1 ChIP-seq in dome } \\
\text { zebrafish embryos, WIG files }\end{array}$ & $\begin{array}{l}\text { (Bogdanovic et al., } \\
\text { 2012) }\end{array}$ & GSM915193 \\
\hline $\begin{array}{l}\text { H3K4me3 ChIP-seq in dome } \\
\text { zebrafish embryos, WIG files }\end{array}$ & $\begin{array}{l}\text { (Bogdanovic et al., } \\
\text { 2012) }\end{array}$ & GSM915189 \\
\hline $\begin{array}{l}\text { H3K27ac ChIP-seq in } 80 \% \text { epiboly } \\
\text { zebrafish embryos, WIG files }\end{array}$ & $\begin{array}{l}\text { (Bogdanovic et al., } \\
\text { 2012) }\end{array}$ & GSM915198 \\
\hline $\begin{array}{l}\text { H3K4me1 ChIP-seq in } 80 \% \text { epiboly } \\
\text { zebrafish embryos, WIG files }\end{array}$ & $\begin{array}{l}\text { (Bogdanovic et al., } \\
\text { 2012) }\end{array}$ & GSM915194 \\
\hline $\begin{array}{l}\text { H3K4me3 ChIP-seq in } 80 \% \text { epiboly } \\
\text { zebrafish embryos, WIG files }\end{array}$ & $\begin{array}{l}\text { (Bogdanovic et al., } \\
\text { 2012) }\end{array}$ & GSM915190 \\
\hline $\begin{array}{l}\text { MNase-seq in } 4.5 \mathrm{hpf} \text { zebrafish } \\
\text { embryos, WIG files }\end{array}$ & (Zhang et al., 2014) & GSM1081554 \\
\hline \multicolumn{3}{|l|}{$\begin{array}{l}\text { Experimental Models: } \\
\text { Organisms/Strains }\end{array}$} \\
\hline Strain EKW & Ekkwill breeders & http://www. ekkwill.com/ \\
\hline \multicolumn{3}{|l|}{ Oligonucleotides } \\
\hline $\begin{array}{l}\text { Gapdh forward primer } \\
\text { TGCTGGTATTGCTCTCAACG }\end{array}$ & & $\mathrm{N} / \mathrm{A}$ \\
\hline $\begin{array}{l}\text { Gapdh reverse primer } \\
\text { AACAGCAAAGGGGTCACATC }\end{array}$ & & $\mathrm{N} / \mathrm{A}$ \\
\hline $\begin{array}{l}\text { GFP forward primer } \\
\text { ATGGTGAGCAAGGGCGAGGAG }\end{array}$ & & $\mathrm{N} / \mathrm{A}$ \\
\hline $\begin{array}{l}\text { GFP reverse primer } \\
\text { TTACTTGTACAGCTCGTCCATG }\end{array}$ & & $\mathrm{N} / \mathrm{A}$ \\
\hline
\end{tabular}




\begin{tabular}{|c|c|c|}
\hline \multicolumn{3}{|l|}{ Recombinant DNA } \\
\hline NF-YA DN in pCS2+ & (Ladam et al., 2018) & $\mathrm{N} / \mathrm{A}$ \\
\hline PBCAB in $\mathrm{pCS} 2+\mathrm{MT}$ & (Choe et al., 2002) & $\mathrm{N} / \mathrm{A}$ \\
\hline tcf3a element in E1b-GFP-Tol2 & This paper & $\mathrm{N} / \mathrm{A}$ \\
\hline tle3a element in E1b-GFP-Tol2 & This paper & $\mathrm{N} / \mathrm{A}$ \\
\hline dachb element in E1b-GFP-Tol2 & This paper & $\mathrm{N} / \mathrm{A}$ \\
\hline fgf8a element in E1b-GFP-Tol2 & This paper & $\mathrm{N} / \mathrm{A}$ \\
\hline yap1 element in E1b-GFP-Tol2 & This paper & $\mathrm{N} / \mathrm{A}$ \\
\hline pax5 element in E1b-GFP-Tol2 & This paper & $\mathrm{N} / \mathrm{A}$ \\
\hline her6 element in E1b-GFP-Tol2 & This paper & $\mathrm{N} / \mathrm{A}$ \\
\hline prdm14 element in E1b-GFP-Tol2 & This paper & $\mathrm{N} / \mathrm{A}$ \\
\hline tcf3a element in $\mathrm{pCR} 8$ & This paper & $\mathrm{N} / \mathrm{A}$ \\
\hline tle3a element in pCR8 & This paper & $\mathrm{N} / \mathrm{A}$ \\
\hline Mutant tcf3a element in pCR8 & This paper & $\mathrm{N} / \mathrm{A}$ \\
\hline Mutant tle3a element in pCR8 & This paper & $\mathrm{N} / \mathrm{A}$ \\
\hline $\begin{array}{l}\text { pTransgenesis p1 gamma- } \\
\text { crystallin::venus GFP }\end{array}$ & (Love et al., 2011) & $\mathrm{N} / \mathrm{A}$ \\
\hline $\begin{array}{l}\text { pTransgenesis p3 sv40 minimal } \\
\text { promoter:: Katushka RFP }\end{array}$ & This paper & $\mathrm{N} / \mathrm{A}$ \\
\hline $\begin{array}{l}\text { pTransgenesis pDest4 Tol2/I-Scel- } \\
\text { CH4-SAR/I-Scel/Tol2/P-element }\end{array}$ & (Love et al., 2011) & $\mathrm{N} / \mathrm{A}$ \\
\hline \multicolumn{3}{|l|}{ Software and Algorithms } \\
\hline FastQC & Babraham Institute & $\begin{array}{l}\text { https://www.bioinformatics. } \\
\text { babraham.ac.uk/projects/fastqc/ } \\
\text { RRID:SCR_014583 }\end{array}$ \\
\hline FastQ Screen & Babraham Institute & $\begin{array}{l}\text { https://www.bioinformatics. } \\
\text { babraham.ac.uk/projects/fastq_screen/ } \\
\text { RRID:SCR_000141 }\end{array}$ \\
\hline Trimmomatic v0.32 & (Bolger et al., 2014) & $\begin{array}{l}\text { http://github.com/timflutre/trimmomatic } \\
\text { RRID:SCR_011848 }\end{array}$ \\
\hline Bowtie v2.2.3 & $\begin{array}{l}\text { (Langmead and } \\
\text { Salzberg, 2012) }\end{array}$ & $\begin{array}{l}\text { http://github.com/BenLangmead/bowtie2 } \\
\text { RRID:SCR_005476 }\end{array}$ \\
\hline SAMtools v0.1.19 & (Li et al., 2009) & $\begin{array}{l}\text { http://github.com/samtools/samtools } \\
\text { RRID:SCR_002105 }\end{array}$ \\
\hline MACS v2.1.0.20140616 & (Zhang et al., 2008) & http://github.com/taoliu/MACS \\
\hline $\begin{array}{l}\text { RSEM v1.2.28, Dolphin, Biocore, } \\
\text { University of Massachusetts } \\
\text { Medical School }\end{array}$ & (Li and Dewey, 2011) & $\begin{array}{l}\text { http://www.umassmed.edu/ } \\
\text { biocore/introducing-dolphin/ } \\
\text { RRID:SCR_013027 }\end{array}$ \\
\hline $\begin{array}{l}\text { DESeq2, Dolphin, Biocore, } \\
\text { University of Massachusetts } \\
\text { Medical School }\end{array}$ & $\begin{array}{l}\text { (Anders and Huber, } \\
\text { 2010) }\end{array}$ & $\begin{array}{l}\text { http://www.umassmed.edu/ } \\
\text { biocore/introducing-dolphin/ } \\
\text { RRID:SCR_015687 }\end{array}$ \\
\hline DEBrowser v v1.12.2 & (Kucukural et al., 2019) & $\begin{array}{l}\text { http://github.com/ } \\
\text { UMMS-Biocore/debrowser }\end{array}$ \\
\hline Galaxy web interface & (Goecks et al., 2010) & $\begin{array}{l}\text { http://usegalaxy.org } \\
\text { RRID:SCR_006281 }\end{array}$ \\
\hline BedTools, Galaxy & $\begin{array}{l}\text { (Quinlan and Hall, } \\
\text { 2010) }\end{array}$ & $\begin{array}{l}\text { http://usegalaxy.org } \\
\text { RRID:SCR_006646 }\end{array}$ \\
\hline
\end{tabular}


bioRxiv preprint doi: https://doi.org/10.1101/720102; this version posted July 31, 2019. The copyright holder for this preprint (which was not certified by peer review) is the author/funder, who has granted bioRxiv a license to display the preprint in perpetuity. It is made available under aCC-BY-NC-ND 4.0 International license.

\begin{tabular}{|l|l|l|}
\hline DeepTools, Galaxy & (Ramirez et al., 2014) & http://usegalaxy.org \\
\hline MEME-ChIP & (Bailey et al., 2009; & http://meme-suite.org/ \\
& Machanick and Bailey, & tools/meme-chip \\
& RRID:SCR_00178 \\
\hline DAVID v6.8 & (Huang da et al., 2009a, & http://david.ncifcrf.gov/ \\
& RRID:SCR_001881 \\
\hline GREAT v3.0.0 & (Hiller et al., 2013; & $\begin{array}{l}\text { http://bejerano.stanford.edu/ } \\
\text { great/public/html } \\
\end{array}$ \\
& McLean et al., 2010) & RRID:SCR_005807 \\
\hline
\end{tabular}




\section{SUPPLEMENTAL FILES}

Figure S1: Related to Figure 2. Identification of NF-Y and/or TALE-dependent genes in zebrafish. (A) Read counts for the RNA-seq analysis. (B, C) Histograms, scatter plots, and Spearman's rank correlation coefficient comparing each biological replicate of NF-YA DN with GFP (B) or PBCAB with GFP (C). (D) Venn diagram showing upregulated genes ( $p$-adj $\leq 0.01 ; F C \geq 1.5$ ) in embryos injected with $P B C A B$ or NF-YA DN. (E-I) GO terms associated with genes upregulated ( $p$-adj $\leq 0.01, F C \geq 1.5$ ) by PBCAB (E), upregulated by NF-YA DN (F), upregulated by both PBCAB and NF-YA DN $(G)$, downregulated exclusively by PBCAB $(H)$ or downregulated exclusively by NFYA DN (I). In E-I, blue bars correspond to transcription-related, green to embryogenesis-related, orange to homeodomain-related, yellow to cilia-related, and gray bars to other ontologies.

Figure S2: Related to Figure 3. Identification of genomic binding sites for NF-Y, and Pbx4 in 3.5hpf zebrafish. (A) Table showing data for Pbx4 and NF-YA ChIP-seq biological replicates with our previous Prep1 ChIP-seq data (Ladam et al., 2018) included as reference. (B) Table showing number of peaks that overlap (at least $1 \mathrm{bp}$ shared between 200bp fragments centered on peaks) between Prep1, Pbx4 and NF-YA ChIP-seq data sets. Only peaks with a 10-fold or greater enrichment over input were considered. (C) Table showing extent of overlap of $\mathrm{Pbx} 4$ peaks with Prep1 peaks and TALE peaks with NF-YA peaks at three different cutoffs (FE $\geq 4, F E \geq 10$ and top $10 \%$ of peaks).

\section{Figure S3: Related to Figure 5. Characterization of NF-Y/TALE-regulated} enhancers in zebrafish. (A-J) GFP-positive offspring from female transgenic carriers for tcf3a:E1b-GFP (A, B), tle3a:E1b-GFP (C, D), dachb:E1b-GFP (E, F), fgf8a:E1b-GFP (G, H), yap1:E1b-GFP (I, J) at 3.5hpf (A, C, E, G, I) and 24hpf (B, D, F, H, J). (K-L) GFP expression in F1 embryos from yap1:E1b-GFP founder \#11 (K) and \#5 (L). (M)

Representative image of a 24hpf GFP-negative embryo. (N-P) UCSC Genome Browser tracks showing NF-YA, Pbx4, and Prep1 ChIP-seq data for the pax5 (N), her6 (O) and prdm14 $(\mathrm{P})$ loci. The diagrams above the tracks show the putative enhancer region in 
green, DECA motifs in orange and CCAAT boxes in blue. (Q) Table summarizing information about each putative enhancer element.

Figure S4: Related to STAR methods section. Sequences of gBlocks used to generate $p$ Transgenesis vectors containing putative enhancers. Sequences are shown for gBlocks encoding wildtype and mutant tcf3a enhancers (A, B), wildtype and mutant tle3a enhancers (C, D) and the minimal SV40 promoter (E). In A-D, green highlights indicate wildtype DECA sites, blue indicate wildtype CCAAT boxes, purple indicate mutant DECA sites and red indicate mutant CCAAT boxes.

Table S1: Related to STAR methods section. Primer sequences used to amplify putative enhancers from zebrafish genomic DNA. 


\section{REFERENCES}

Amin, S., Donaldson, I.J., Zannino, D.A., Hensman, J., Rattray, M., Losa, M., Spitz, F., Ladam, F., Sagerstrom, C., and Bobola, N. (2015). Hoxa2 selectively enhances Meis binding to change a branchial arch ground state. Dev Cell 32, 265-277.

Anders, S., and Huber, W. (2010). Differential expression analysis for sequence count data. Genome Biol 11, R106.

Bailey, T.L., Boden, M., Buske, F.A., Frith, M., Grant, C.E., Clementi, L., Ren, J., Li, W.W., and Noble, W.S. (2009). MEME SUITE: tools for motif discovery and searching. Nucleic Acids Res 37, W202-208.

Bhattacharya, A., Deng, J.M., Zhang, Z., Behringer, R., de Crombrugghe, B., and Maity, S.N. (2003). The B subunit of the CCAAT box binding transcription factor complex (CBF/NF-Y) is essential for early mouse development and cell proliferation. Cancer Res 63, 8167-8172.

Birnbaum, R.Y., Clowney, E.J., Agamy, O., Kim, M.J., Zhao, J., Yamanaka, T., Pappalardo, Z., Clarke, S.L., Wenger, A.M., Nguyen, L., et al. (2012). Coding exons function as tissue-specific enhancers of nearby genes. Genome Res 22, 1059-1068. Bogdanovic, O., Fernandez-Minan, A., Tena, J.J., de la Calle-Mustienes, E., Hidalgo, C., van Kruysbergen, I., van Heeringen, S.J., Veenstra, G.J., and Gomez-Skarmeta, J.L. (2012). Dynamics of enhancer chromatin signatures mark the transition from pluripotency to cell specification during embryogenesis. Genome Res 22, 2043-2053. Bolger, A.M., Lohse, M., and Usadel, B. (2014). Trimmomatic: a flexible trimmer for Illumina sequence data. Bioinformatics 30, 2114-2120.

Chang, C.P., Jacobs, Y., Nakamura, T., Jenkins, N.A., Copeland, N.G., and Cleary, M.L. (1997). Meis proteins are major in vivo DNA binding partners for wild-type but not chimeric Pbx proteins. Mol Cell Biol 17, 5679-5687.

Chen, Y.H., Lin, Y.T., and Lee, G.H. (2009). Novel and unexpected functions of zebrafish CCAAT box binding transcription factor (NF-Y) B subunit during cartilages development. Bone 44, 777-784.

Chen, Z., and Zhang, Y. (2019). Loss of DUX causes minor defects in zygotic genome activation and is compatible with mouse development. Nat Genet 51, 947-951. 
Choe, S.K., Ladam, F., and Sagerstrom, C.G. (2014). TALE factors poise promoters for activation by Hox proteins. Dev Cell 28, 203-211.

Choe, S.K., Lu, P., Nakamura, M., Lee, J., and Sagerstrom, C.G. (2009). Meis cofactors control HDAC and CBP accessibility at Hox-regulated promoters during zebrafish embryogenesis. Dev Cell 17, 561-567.

Choe, S.K., Vlachakis, N., and Sagerstrom, C.G. (2002). Meis family proteins are required for hindbrain development in the zebrafish. Development 129, 585-595.

Cirillo, L.A., Lin, F.R., Cuesta, I., Friedman, D., Jarnik, M., and Zaret, K.S. (2002). Opening of compacted chromatin by early developmental transcription factors HNF3 (FoxA) and GATA-4. Mol Cell 9, 279-289.

De laco, A., Coudray, A., Duc, J., and Trono, D. (2019). DPPA2 and DPPA4 are necessary to establish a 2C-like state in mouse embryonic stem cells. EMBO Rep 20. De laco, A., Planet, E., Coluccio, A., Verp, S., Duc, J., and Trono, D. (2017). DUXfamily transcription factors regulate zygotic genome activation in placental mammals. Nat Genet 49, 941-945.

Deflorian, G., Tiso, N., Ferretti, E., Meyer, D., Blasi, F., Bortolussi, M., and Argenton, F. (2004). Prep1.1 has essential genetic functions in hindbrain development and cranial neural crest cell differentiation. Development 131, 613-627.

Dolfini, D., Gatta, R., and Mantovani, R. (2012). NF-Y and the transcriptional activation of CCAAT promoters. Crit Rev Biochem Mol Biol 47, 29-49.

Eckersley-Maslin, M., Alda-Catalinas, C., Blotenburg, M., Kreibich, E., Krueger, C., and Reik, W. (2019). Dppa2 and Dppa4 directly regulate the Dux-driven zygotic transcriptional program. Genes Dev 33, 194-208.

Essner, J.J., Vogan, K.J., Wagner, M.K., Tabin, C.J., Yost, H.J., and Brueckner, M. (2002). Conserved function for embryonic nodal cilia. Nature 418, 37-38.

Ferretti, E., Cambronero, F., Tumpel, S., Longobardi, E., Wiedemann, L.M., Blasi, F., and Krumlauf, R. (2005). Hoxb1 enhancer and control of rhombomere 4 expression: complex interplay between PREP1-PBX1-HOXB1 binding sites. Mol Cell Biol 25, 85418552.

Ferretti, E., Marshall, H., Popperl, H., Maconochie, M., Krumlauf, R., and Blasi, F. (2000). Segmental expression of Hoxb2 in r4 requires two separate sites that integrate 
cooperative interactions between Prep1, Pbx and Hox proteins. Development 127, 155166.

Gagnon, J.A., Obbad, K., and Schier, A.F. (2018). The primary role of zebrafish nanog is in extra-embryonic tissue. Development 145.

Gao, L., Wu, K., Liu, Z., Yao, X., Yuan, S., Tao, W., Yi, L., Yu, G., Hou, Z., Fan, D., et al. (2018). Chromatin Accessibility Landscape in Human Early Embryos and Its Association with Evolution. Cell 173, 248-259 e215.

Goecks, J., Nekrutenko, A., Taylor, J., and Galaxy, T. (2010). Galaxy: a comprehensive approach for supporting accessible, reproducible, and transparent computational research in the life sciences. Genome Biol 11, R86.

Grieder, N.C., Marty, T., Ryoo, H.D., Mann, R.S., and Affolter, M. (1997). Synergistic activation of a Drosophila enhancer by HOM/EXD and DPP signaling. EMBO J 16, 7402-7410.

Gualdi, R., Bossard, P., Zheng, M., Hamada, Y., Coleman, J.R., and Zaret, K.S. (1996). Hepatic specification of the gut endoderm in vitro: cell signaling and transcriptional control. Genes Dev 10, 1670-1682.

Harrison, M.M., Li, X.Y., Kaplan, T., Botchan, M.R., and Eisen, M.B. (2011). Zelda binding in the early Drosophila melanogaster embryo marks regions subsequently activated at the maternal-to-zygotic transition. PLoS Genet 7, e1002266.

Heinz, S., Benner, C., Spann, N., Bertolino, E., Lin, Y.C., Laslo, P., Cheng, J.X., Murre, C., Singh, H., and Glass, C.K. (2010). Simple combinations of lineage-determining transcription factors prime cis-regulatory elements required for macrophage and $B$ cell identities. Mol Cell 38, 576-589.

Hendrickson, P.G., Dorais, J.A., Grow, E.J., Whiddon, J.L., Lim, J.W., Wike, C.L., Weaver, B.D., Pflueger, C., Emery, B.R., Wilcox, A.L., et al. (2017). Conserved roles of mouse DUX and human DUX4 in activating cleavage-stage genes and MERVL/HERVL retrotransposons. Nat Genet 49, 925-934.

Hiller, M., Agarwal, S., Notwell, J.H., Parikh, R., Guturu, H., Wenger, A.M., and Bejerano, G. (2013). Computational methods to detect conserved non-genic elements in phylogenetically isolated genomes: application to zebrafish. Nucleic Acids Res 41, e151. 
Huang da, W., Sherman, B.T., and Lempicki, R.A. (2009a). Bioinformatics enrichment tools: paths toward the comprehensive functional analysis of large gene lists. Nucleic Acids Res 37, 1-13.

Huang da, W., Sherman, B.T., and Lempicki, R.A. (2009b). Systematic and integrative analysis of large gene lists using DAVID bioinformatics resources. Nat Protoc 4, 44-57. Iwafuchi-Doi, M., and Zaret, K.S. (2016). Cell fate control by pioneer transcription factors. Development 143, 1833-1837.

Jacobs, Y., Schnabel, C.A., and Cleary, M.L. (1999). Trimeric association of Hox and TALE homeodomain proteins mediates Hoxb2 hindbrain enhancer activity. Mol Cell Biol 19, 5134-5142.

Knoepfler, P.S., and Kamps, M.P. (1997). The highest affinity DNA element bound by Pbx complexes in $\mathrm{t}(1 ; 19)$ leukemic cells fails to mediate cooperative DNA-binding or cooperative transactivation by E2a-Pbx1 and class I Hox proteins - evidence for selective targetting of $\mathrm{E} 2 \mathrm{a}-\mathrm{Pbx} 1$ to a subset of Pbx-recognition elements. Oncogene 14, 2521-2531.

Kucukural, A., Yukselen, O., Ozata, D.M., Moore, M.J., and Garber, M. (2019).

DEBrowser: interactive differential expression analysis and visualization tool for count data. BMC Genomics 20, 6.

Ladam, F., and Sagerstrom, C.G. (2014). Hox regulation of transcription: more complex(es). Dev Dyn 243, 4-15.

Ladam, F., Stanney, W., Donaldson, I.J., Yildiz, O., Bobola, N., and Sagerstrom, C.G. (2018). TALE factors use two distinct functional modes to control an essential zebrafish gene expression program. Elife 7.

Langmead, B., and Salzberg, S.L. (2012). Fast gapped-read alignment with Bowtie 2. Nat Methods 9, 357-359.

Lee, M.T., Bonneau, A.R., Takacs, C.M., Bazzini, A.A., DiVito, K.R., Fleming, E.S., and Giraldez, A.J. (2013). Nanog, Pou5f1 and SoxB1 activate zygotic gene expression during the maternal-to-zygotic transition. Nature 503, 360-364.

Leichsenring, M., Maes, J., Mossner, R., Driever, W., and Onichtchouk, D. (2013).

Pou5f1 transcription factor controls zygotic gene activation in vertebrates. Science 341 , 1005-1009. 
Li, B., and Dewey, C.N. (2011). RSEM: accurate transcript quantification from RNA-Seq data with or without a reference genome. BMC Bioinformatics 12, 323.

Li, H., Handsaker, B., Wysoker, A., Fennell, T., Ruan, J., Homer, N., Marth, G., Abecasis, G., Durbin, R., and Genome Project Data Processing, S. (2009). The Sequence Alignment/Map format and SAMtools. Bioinformatics 25, 2078-2079. Li, Q., Ritter, D., Yang, N., Dong, Z., Li, H., Chuang, J.H., and Guo, S. (2010). A systematic approach to identify functional motifs within vertebrate developmental enhancers. Dev Biol 337, 484-495.

Liang, H.L., Nien, C.Y., Liu, H.Y., Metzstein, M.M., Kirov, N., and Rushlow, C. (2008). The zinc-finger protein Zelda is a key activator of the early zygotic genome in Drosophila. Nature 456, 400-403.

Love, N.R., Thuret, R., Chen, Y., Ishibashi, S., Sabherwal, N., Paredes, R., Alves-Silva, J., Dorey, K., Noble, A.M., Guille, M.J., et al. (2011). pTransgenesis: a cross-species, modular transgenesis resource. Development 138, 5451-5458.

Lu, F., Liu, Y., Inoue, A., Suzuki, T., Zhao, K., and Zhang, Y. (2016). Establishing Chromatin Regulatory Landscape during Mouse Preimplantation Development. Cell 165, 1375-1388.

Machanick, P., and Bailey, T.L. (2011). MEME-ChIP: motif analysis of large DNA datasets. Bioinformatics 27, 1696-1697.

Magnani, L., Ballantyne, E.B., Zhang, X., and Lupien, M. (2011). PBX1 genomic pioneer function drives ERalpha signaling underlying progression in breast cancer. PLoS Genet 7, e1002368.

Maity, S.N., and de Crombrugghe, B. (1998). Role of the CCAAT-binding protein CBF/NF-Y in transcription. Trends Biochem Sci 23, 174-178.

Mantovani, R., Li, X.Y., Pessara, U., Hooft van Huisjduijnen, R., Benoist, C., and Mathis, D. (1994). Dominant negative analogs of NF-YA. J Biol Chem 269, 2034020346.

McLean, C.Y., Bristor, D., Hiller, M., Clarke, S.L., Schaar, B.T., Lowe, C.B., Wenger, A.M., and Bejerano, G. (2010). GREAT improves functional interpretation of cisregulatory regions. Nat Biotechnol 28, 495-501. 
Merabet, S., and Mann, R.S. (2016). To Be Specific or Not: The Critical Relationship Between Hox And TALE Proteins. Trends Genet 32, 334-347.

Nardini, M., Gnesutta, N., Donati, G., Gatta, R., Forni, C., Fossati, A., Vonrhein, C., Moras, D., Romier, C., Bolognesi, M., et al. (2013). Sequence-specific transcription factor NF-Y displays histone-like DNA binding and H2B-like ubiquitination. Cell 152, 132-143.

Nepal, C., Hadzhiev, Y., Previti, C., Haberle, V., Li, N., Takahashi, H., Suzuki, A.M., Sheng, Y., Abdelhamid, R.F., Anand, S., et al. (2013). Dynamic regulation of the transcription initiation landscape at single nucleotide resolution during vertebrate embryogenesis. Genome Res 23, 1938-1950.

Nien, C.Y., Liang, H.L., Butcher, S., Sun, Y., Fu, S., Gocha, T., Kirov, N., Manak, J.R., and Rushlow, C. (2011). Temporal coordination of gene networks by Zelda in the early Drosophila embryo. PLoS Genet 7, e1002339.

Oldfield, A.J., Yang, P., Conway, A.E., Cinghu, S., Freudenberg, J.M., Yellaboina, S., and Jothi, R. (2014). Histone-fold domain protein NF-Y promotes chromatin accessibility for cell type-specific master transcription factors. Mol Cell 55, 708-722.

Penkov, D., Mateos San Martin, D., Fernandez-Diaz, L.C., Rossello, C.A., Torroja, C., Sanchez-Cabo, F., Warnatz, H.J., Sultan, M., Yaspo, M.L., Gabrieli, A., et al. (2013). Analysis of the DNA-binding profile and function of TALE homeoproteins reveals their specialization and specific interactions with Hox genes/proteins. Cell Rep 3, 1321-1333. Popperl, H., Bienz, M., Studer, M., Chan, S.K., Aparicio, S., Brenner, S., Mann, R.S., and Krumlauf, R. (1995). Segmental expression of Hoxb-1 is controlled by a highly conserved autoregulatory loop dependent upon exd/pbx. Cell 81, 1031-1042.

Popperl, H., Rikhof, H., Chang, H., Haffter, P., Kimmel, C.B., and Moens, C.B. (2000). lazarus is a novel pbx gene that globally mediates hox gene function in zebrafish. Mol Cell 6, 255-267.

Prince, V.E., Joly, L., Ekker, M., and Ho, R.K. (1998a). Zebrafish hox genes: genomic organization and modified colinear expression patterns in the trunk. Development 125 , 407-420. 
Prince, V.E., Moens, C.B., Kimmel, C.B., and Ho, R.K. (1998b). Zebrafish hox genes: expression in the hindbrain region of wild-type and mutants of the segmentation gene, valentino. Development 125, 393-406.

Quinlan, A.R., and Hall, I.M. (2010). BEDTools: a flexible suite of utilities for comparing genomic features. Bioinformatics 26, 841-842.

Ramirez, F., Dundar, F., Diehl, S., Gruning, B.A., and Manke, T. (2014). deepTools: a flexible platform for exploring deep-sequencing data. Nucleic Acids Res 42, W187-191. Ryoo, H.D., and Mann, R.S. (1999). The control of trunk Hox specificity and activity by Extradenticle. Genes Dev 13, 1704-1716.

Saleh, M., Rambaldi, I., Yang, X.J., and Featherstone, M.S. (2000). Cell signaling switches HOX-PBX complexes from repressors to activators of transcription mediated by histone deacetylases and histone acetyltransferases. Mol Cell Biol 20, 8623-8633. Schulz, K.N., Bondra, E.R., Moshe, A., Villalta, J.E., Lieb, J.D., Kaplan, T., McKay, D.J., and Harrison, M.M. (2015). Zelda is differentially required for chromatin accessibility, transcription factor binding, and gene expression in the early Drosophila embryo. Genome Res 25, 1715-1726.

Soufi, A., Donahue, G., and Zaret, K.S. (2012). Facilitators and impediments of the pluripotency reprogramming factors' initial engagement with the genome. Cell 151, 9941004.

Soufi, A., Garcia, M.F., Jaroszewicz, A., Osman, N., Pellegrini, M., and Zaret, K.S. (2015). Pioneer transcription factors target partial DNA motifs on nucleosomes to initiate reprogramming. Cell 161, 555-568.

Sun, Y., Nien, C.Y., Chen, K., Liu, H.Y., Johnston, J., Zeitlinger, J., and Rushlow, C. (2015). Zelda overcomes the high intrinsic nucleosome barrier at enhancers during Drosophila zygotic genome activation. Genome Res 25, 1703-1714.

Tumpel, S., Cambronero, F., Ferretti, E., Blasi, F., Wiedemann, L.M., and Krumlauf, R. (2007). Expression of Hoxa2 in rhombomere 4 is regulated by a conserved crossregulatory mechanism dependent upon Hoxb1. Dev Biol 302, 646-660.

Tyner, C., Barber, G.P., Casper, J., Clawson, H., Diekhans, M., Eisenhart, C., Fischer, C.M., Gibson, D., Gonzalez, J.N., Guruvadoo, L., et al. (2017). The UCSC Genome Browser database: 2017 update. Nucleic Acids Res 45, D626-D634. 
Vastenhouw, N.L., Cao, W.X., and Lipshitz, H.D. (2019). The maternal-to-zygotic transition revisited. Development 146.

Vlachakis, N., Ellstrom, D.R., and Sagerstrom, C.G. (2000). A novel pbx family member expressed during early zebrafish embryogenesis forms trimeric complexes with Meis3 and Hoxb1b. Dev Dyn 217, 109-119.

Waskiewicz, A.J., Rikhof, H.A., Hernandez, R.E., and Moens, C.B. (2001). Zebrafish Meis functions to stabilize $\mathrm{Pbx}$ proteins and regulate hindbrain patterning. Development $128,4139-4151$.

Waskiewicz, A.J., Rikhof, H.A., and Moens, C.B. (2002). Eliminating zebrafish pbx proteins reveals a hindbrain ground state. Dev Cell 3, 723-733.

Zhang, Y., Liu, T., Meyer, C.A., Eeckhoute, J., Johnson, D.S., Bernstein, B.E., Nusbaum, C., Myers, R.M., Brown, M., Li, W., et al. (2008). Model-based analysis of ChIP-Seq (MACS). Genome Biol 9, R137.

Zhang, Y., Vastenhouw, N.L., Feng, J., Fu, K., Wang, C., Ge, Y., Pauli, A., van Hummelen, P., Schier, A.F., and Liu, X.S. (2014). Canonical nucleosome organization at promoters forms during genome activation. Genome Res 24, 260-266. 


\section{Figure 1}
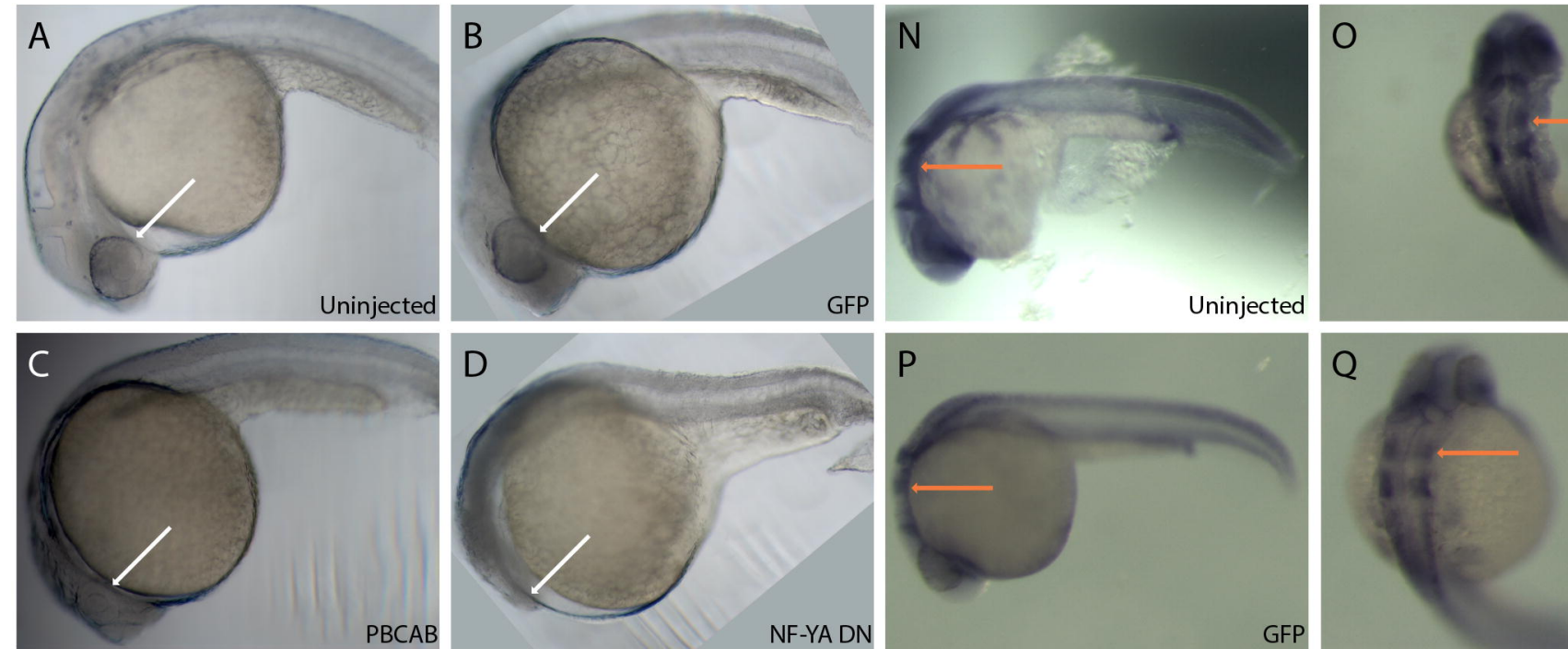

GFP
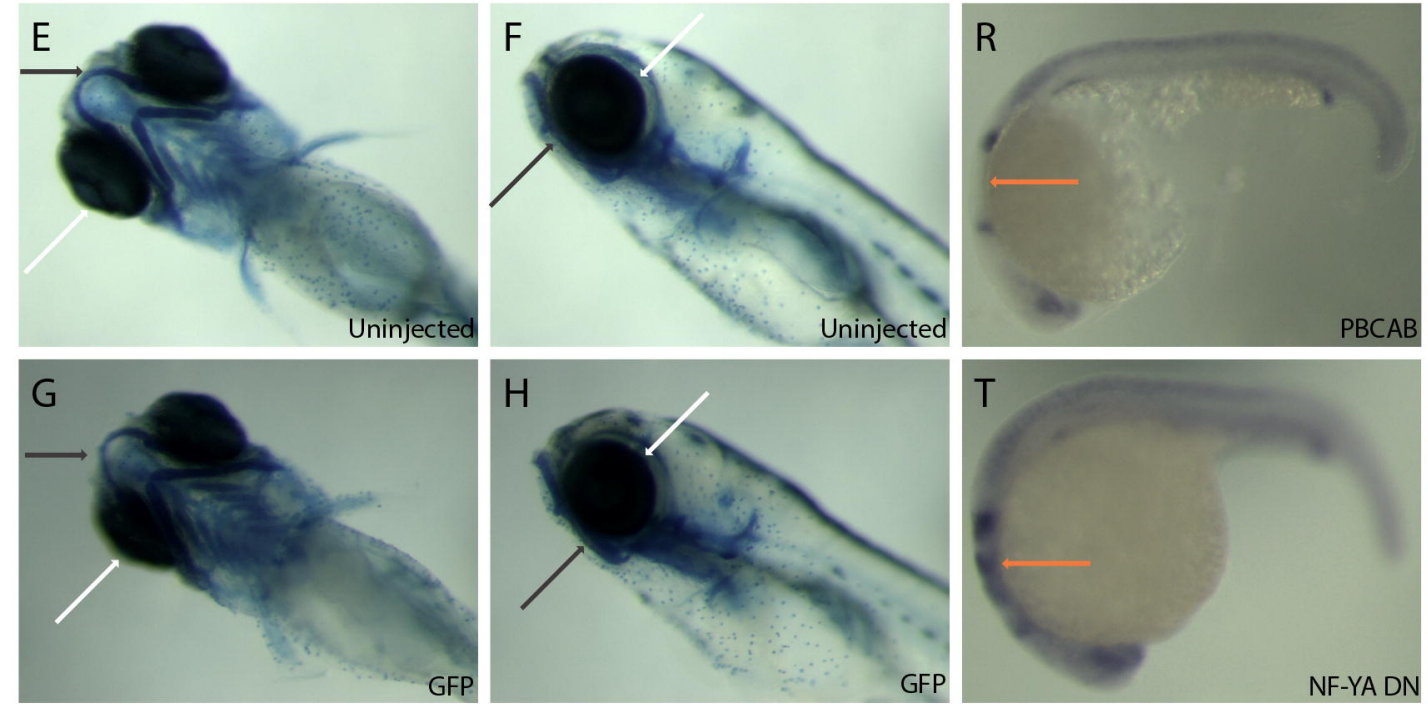$$
1
$$

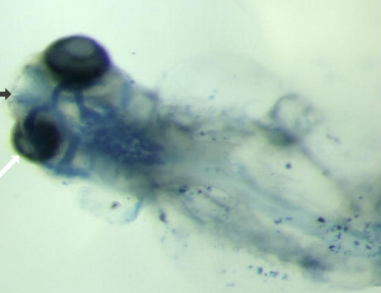

PBCAB
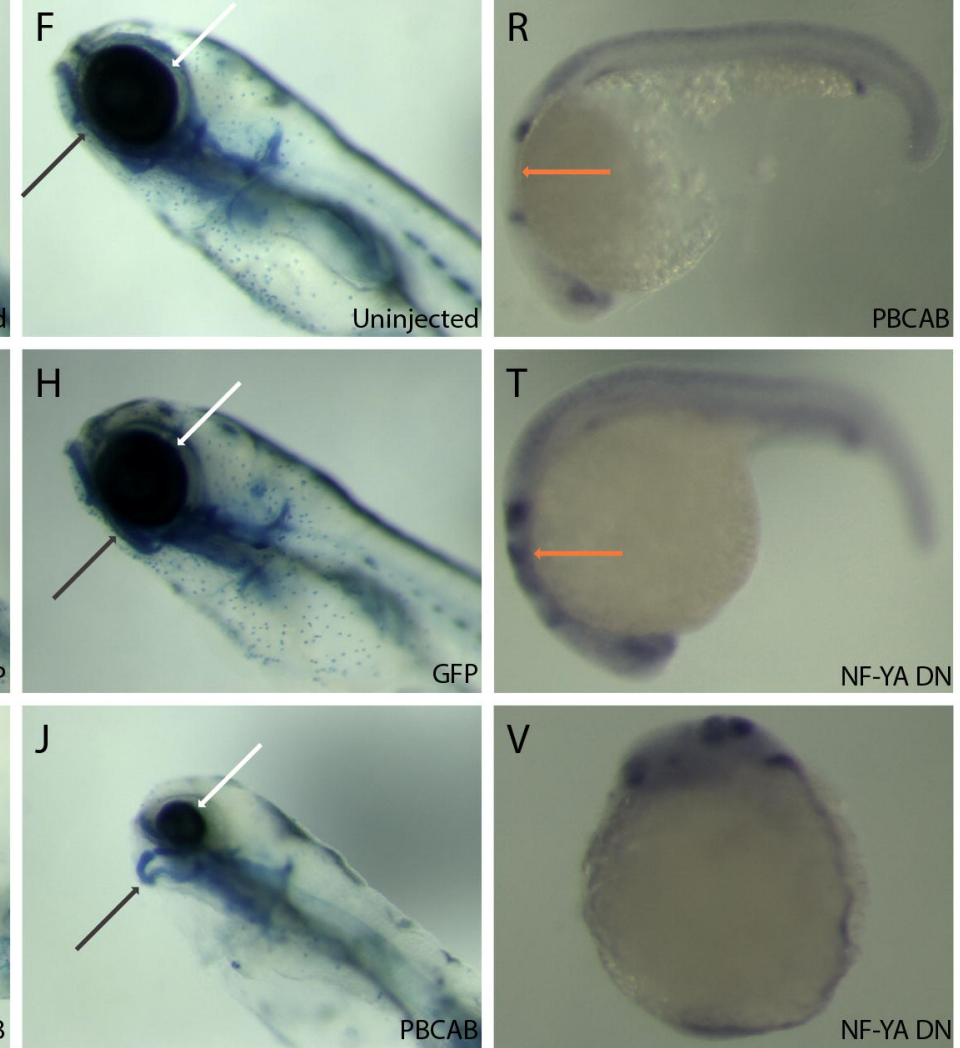

NF-YA DN

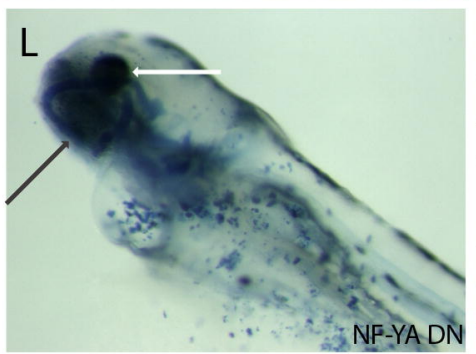

X

\begin{tabular}{|l|c|c|c|c|}
\hline & Uninjected & GFP & NF-YA DN & PBCAB \\
\hline Two Eyes & $65(100 \%)$ & $48(78.7 \%)$ & $18(50.0 \%)$ & $46(73.0 \%)$ \\
\hline $\begin{array}{l}\text { No Eye/ Anterior } \\
\text { Truncation }\end{array}$ & $0(0 \%)$ & $0(0 \%)$ & $10(27.8 \%)$ & $12(19.0 \%)$ \\
\hline Grossly Abnormal & $0(0 \%)$ & $13(21.3 \%)$ & $8(22.2 \%)$ & $5(8.0 \%)$ \\
\hline Total & 65 & 61 & 36 & 63 \\
\hline
\end{tabular}

$Y$

M

\begin{tabular}{|l|c|c|c|c|}
\hline & Uninjected & GFP & NF-YA DN & PBCAB \\
\hline Normal & $77(100 \%)$ & $54(100 \%)$ & $26(47.3 \%)$ & $11(21.2 \%)$ \\
\hline Abnormal & $0(0 \%)$ & $0(0 \%)$ & $29(52.7 \%)$ & $41(78.8 \%)$ \\
\hline Total & 77 & 54 & 55 & 52 \\
\hline
\end{tabular}

\begin{tabular}{|c|c|c|c|c|}
\hline & Uninjected & GFP & NF-YA DN & PBCAB \\
\hline Normal & $59(90.8 \%)$ & $48(78.7 \%)$ & $28(77.7 \%)$ & $13(20.6 \%)$ \\
\hline Missing r3 & $0(0 \%)$ & $0(0 \%)$ & $0(0 \%)$ & $33(52.4 \%)$ \\
\hline Poor Signal & $6(9.2 \%)$ & $13(21.3 \%)$ & $8(22.2 \%)$ & $17(27.0 \%)$ \\
\hline Total & 65 & 61 & 36 & 63 \\
\hline
\end{tabular}


Figure 3
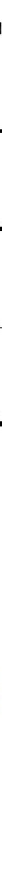

E
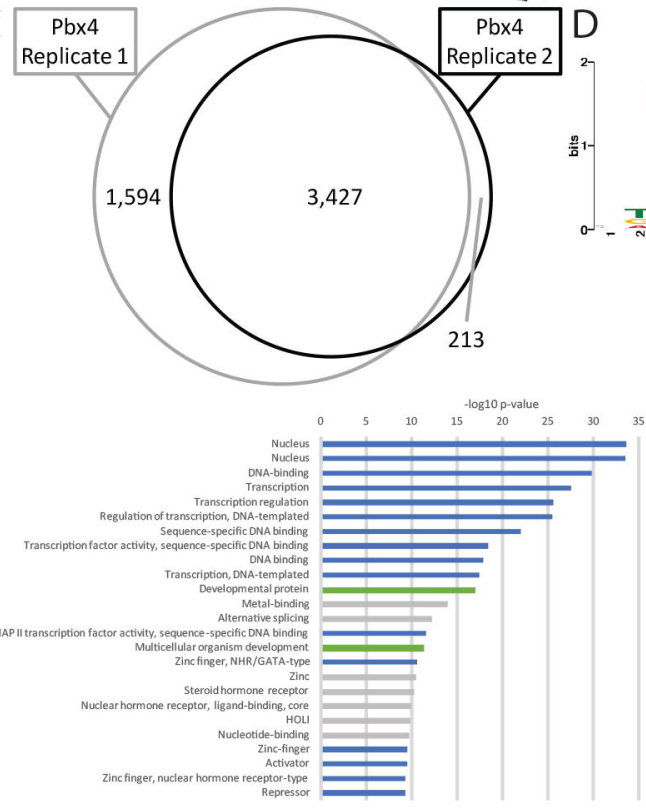

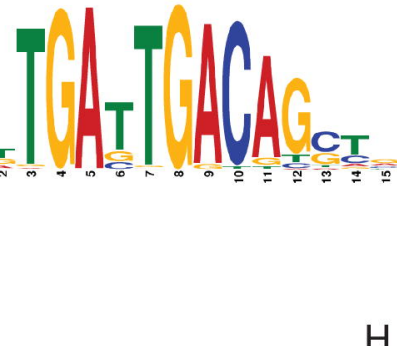

$\mathrm{H}$

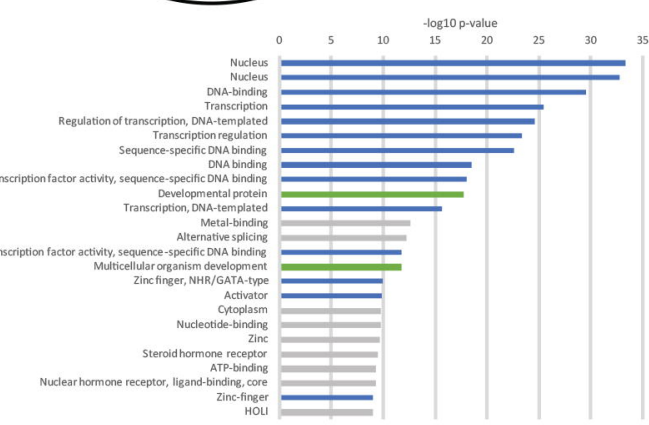

I

0
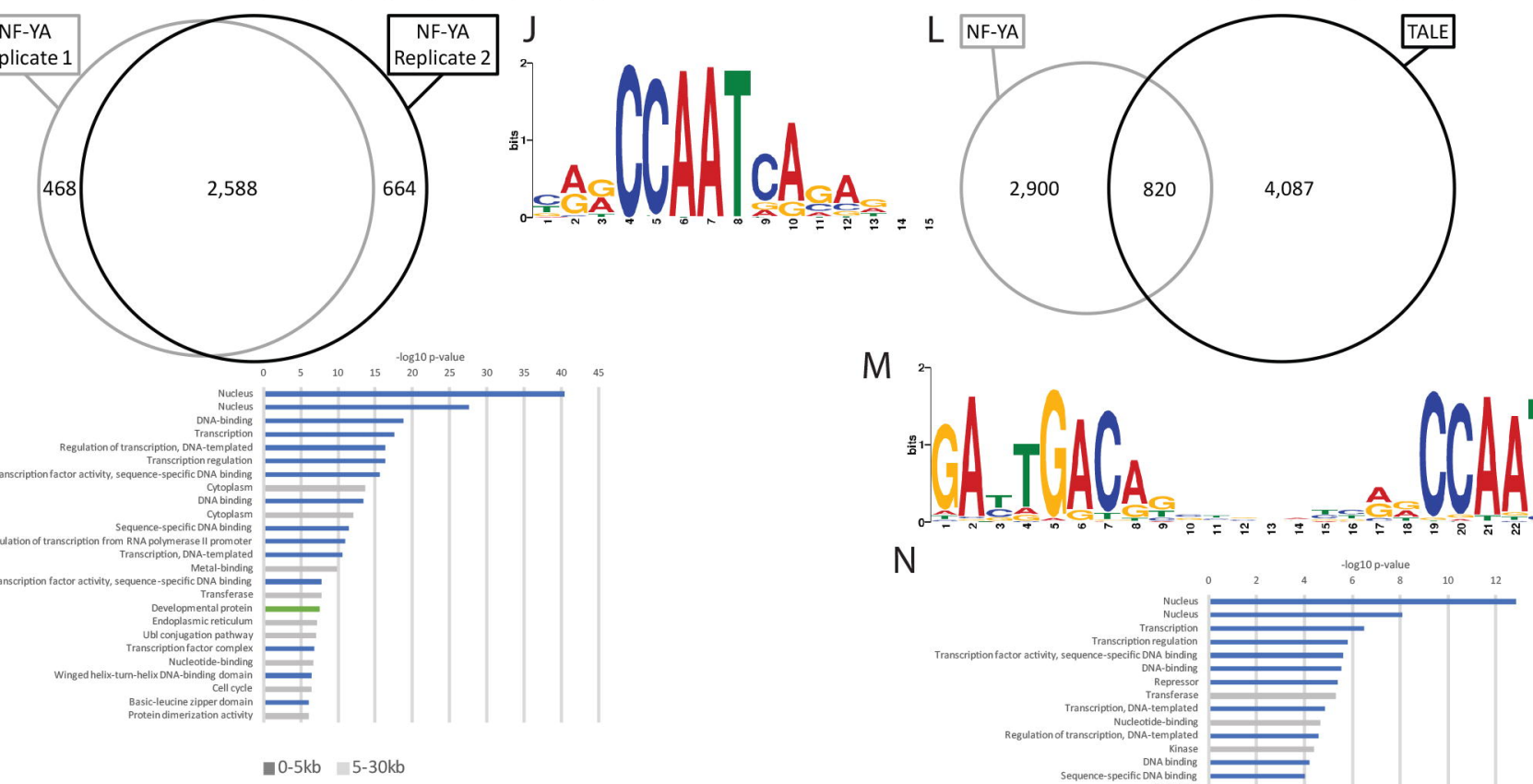

M
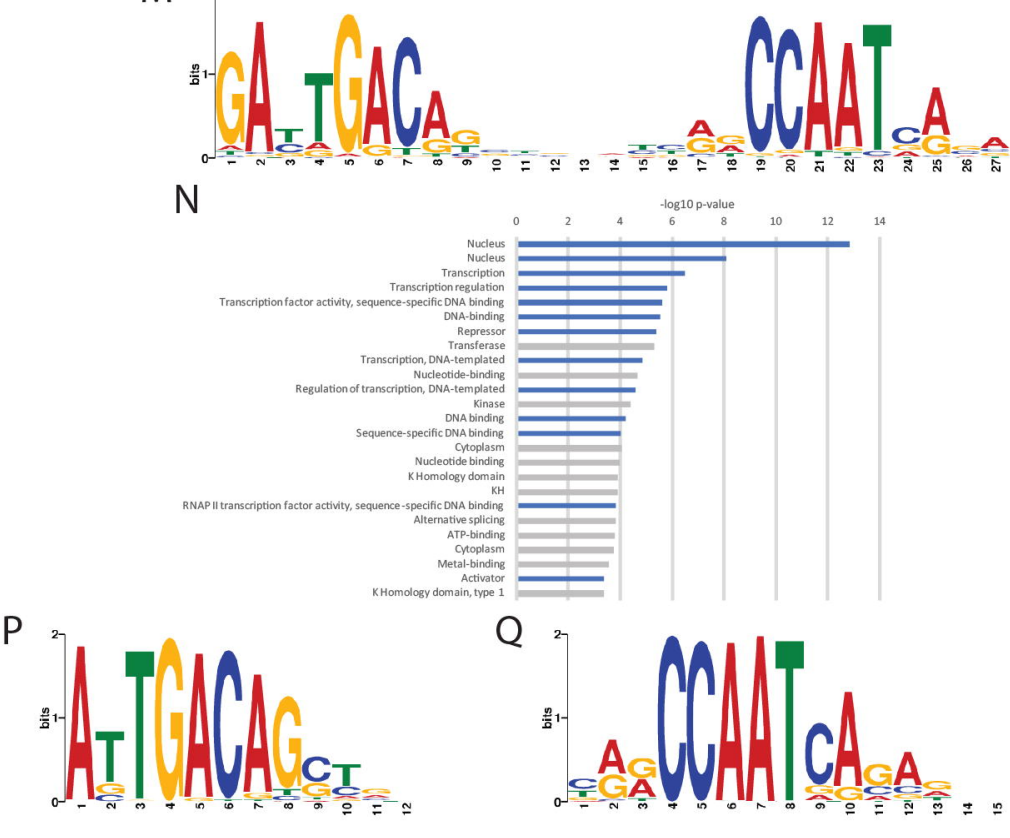
Figure 4

A

B

\begin{tabular}{|l|l|l|l|}
\hline ChIP-seq & TALE-Dependent & NF-Y-Dependent & TALE/NF-Y-Dependent \\
\hline TALE & $51.9 \%(335 / 646)$ & $48.6 \%(158 / 325)$ & $50 \%(37 / 74)$ \\
\hline NFYA & $55.4 \%(358 / 646)$ & $61.2 \%(199 / 325)$ & $70.3 \%(52 / 74)$ \\
\hline TALE/NF-Y & $40.9 \%(264 / 646)$ & $41.5 \%(135 / 325)$ & $48.6 \%(36 / 74)$ \\
\hline
\end{tabular}

C

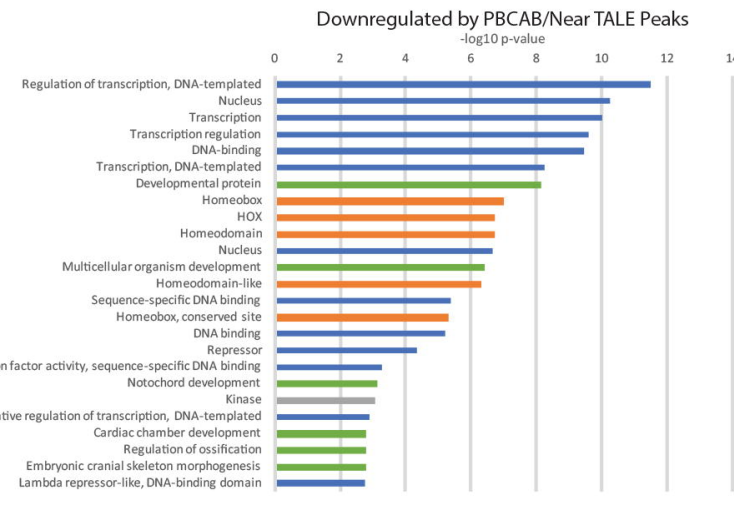

$E$

Downregulated by PBCAB and NF-YA DN/Near TALE and NF-YA Peaks
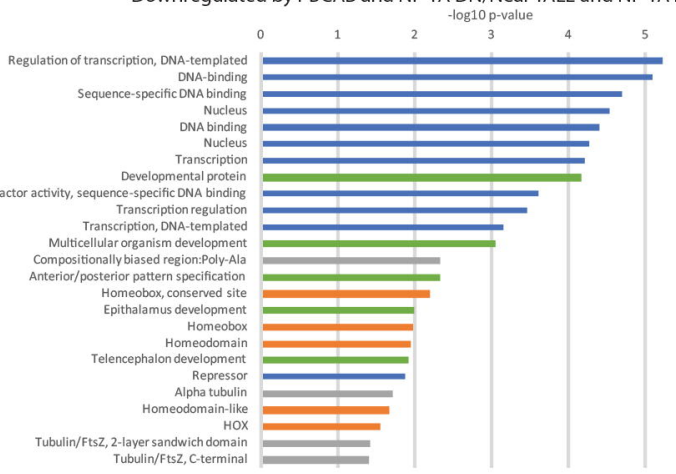

G

Near TALE/NF-Y peak No TALE/NF-Y peak

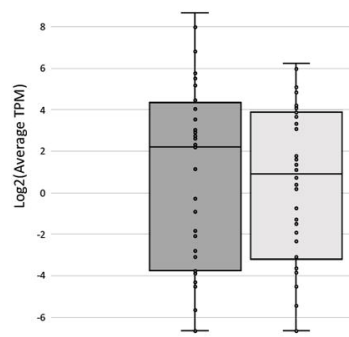

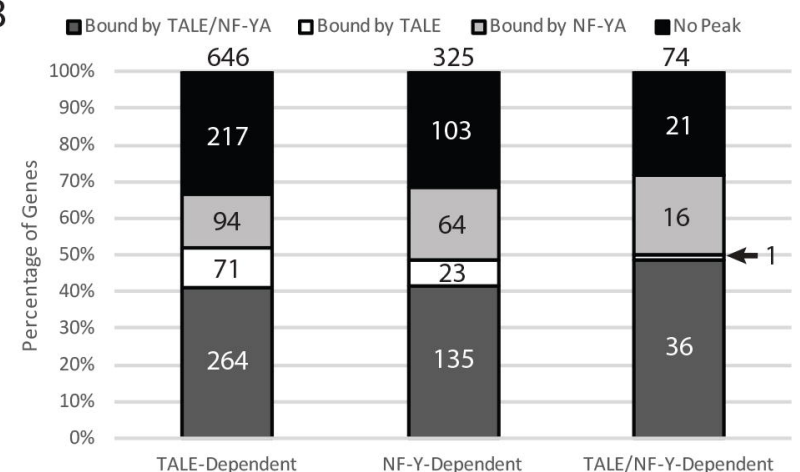

D

Downregulated by NF-YA DN/Near NF-YA Peaks

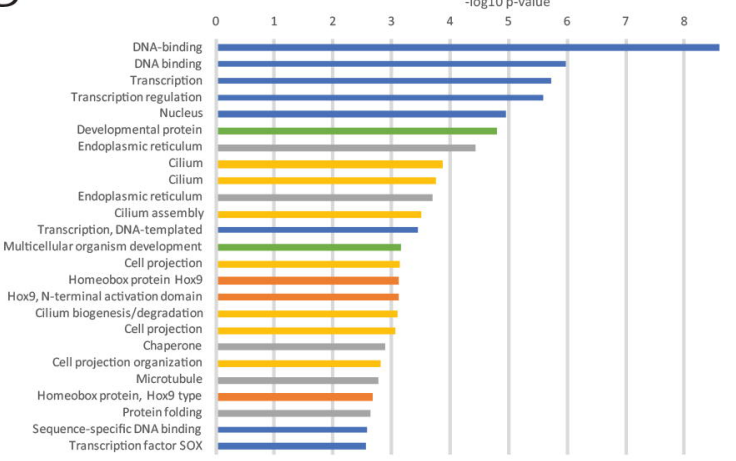

$\mathrm{F}$

Downregulated by PBCAB and NF-YA DN/Near Overlapping TALE and NF-YA Peaks

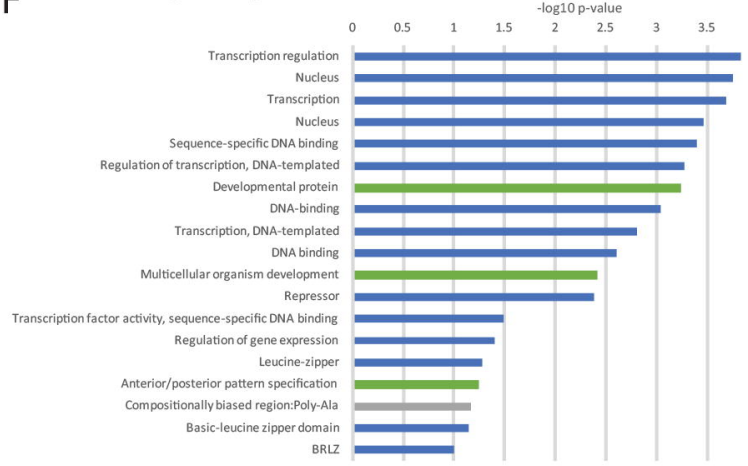


Figure 5

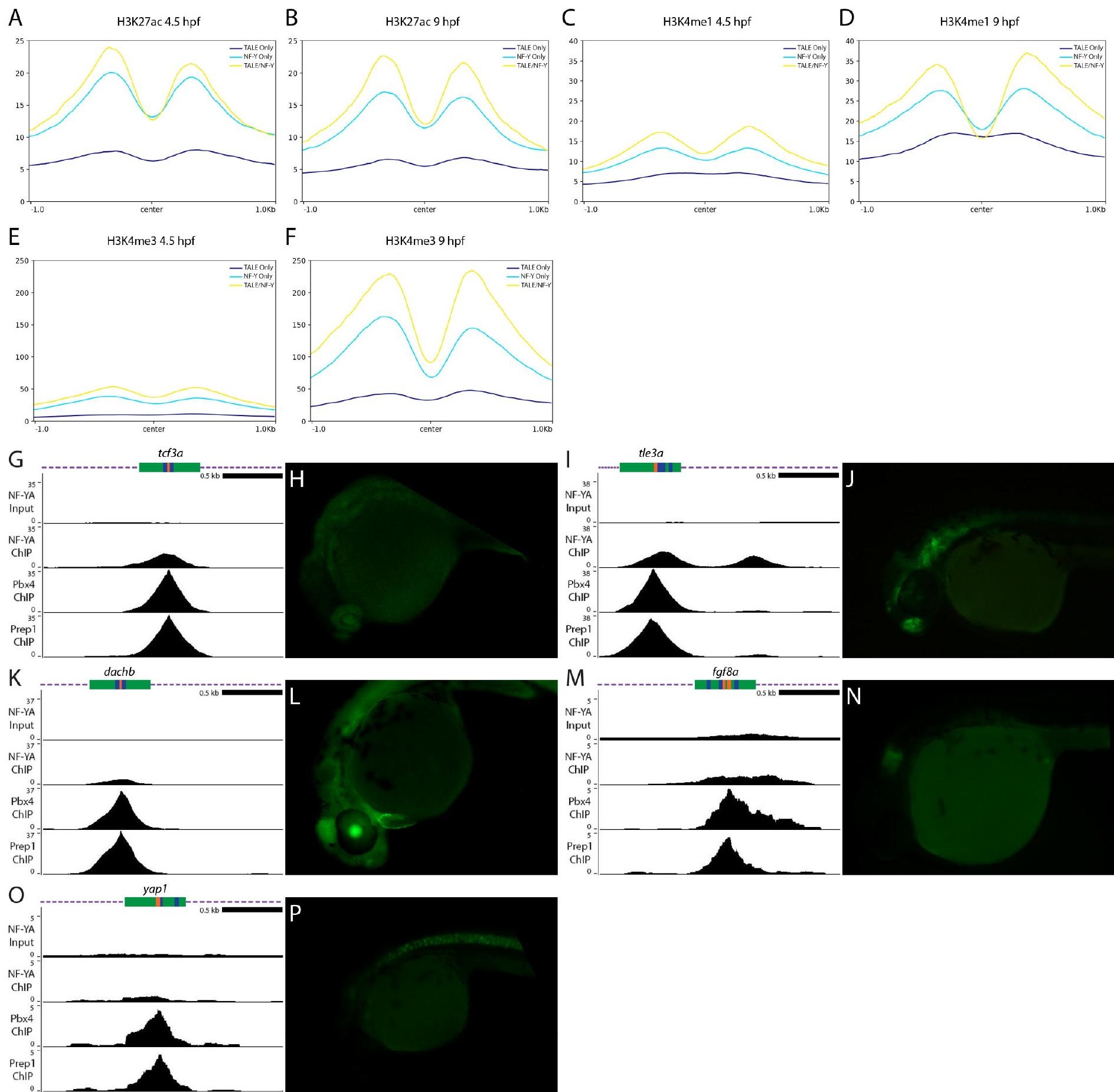


